\title{
Article \\ Analysis of the Low Cycle Fatigue Behavior of DP980 Steel Gas Metal Arc Welded Joints
}

\author{
Juliana G. Rosado-Carrasco, Walter F. González-Zapatero, Christian J. García, César M. Gómora, David Jaramillo \\ and Ricardo R. Ambriz *(i)
}

Citation: Rosado-Carrasco, J.G.; González-Zapatero, W.F.; García, C.J.; Gómora, C.M.; Jaramillo, D.; Ambriz, R.R. Analysis of the Low Cycle Fatigue Behavior of DP980 Steel Gas Metal Arc Welded Joints. Metals 2022, 12, 419. https://doi.org/10.3390/ met12030419

Academic Editor: Xiangdong Gao

Received: 31 January 2022

Accepted: 18 February 2022

Published: 27 February 2022

Publisher's Note: MDPI stays neutral with regard to jurisdictional claims in published maps and institutional affiliations.

Copyright: (C) 2022 by the authors. Licensee MDPI, Basel, Switzerland. This article is an open access article distributed under the terms and conditions of the Creative Commons Attribution (CC BY) license (https:// creativecommons.org/licenses/by/ $4.0 /)$.
Instituto Politécnico Nacional CIITEC-IPN, Cerrada de Cecati S/N Col. Sta. Catarina, Azcapotzalco, Mexico City 02250, Mexico; jrosadoc1900@alumno.ipn.mx (J.G.R.-C.); wgonzalezz@ipn.mx (W.F.G.-Z.); cjgarcia@ipn.mx (C.J.G.); cmendozago@ipn.mx (C.M.G.); djaramillo@ipn.mx (D.J.)

* Correspondence: rrambriz@ipn.mx

\begin{abstract}
Dual phase (DP) steels have high strength, while maintaining outstanding elongation capacities. This is possible using a well-controlled thermomechanical process that produces a perfect phase combination in the DP microstructures. However, automotive makers are required to weld the DP steels, which generates a soft zone in the microstructure. In this work, 1.6 mm-thick DP980 steel sheets were welded by gas metal arc welding process to analyze the response of the welded soft zone to cyclic loading conditions. Conducted macrographic and metallography analyses revealed good quality in the appearance of the welded joints, with a complete fusion of the DP980 joint and without the presence of discontinuities. Low cycle fatigue tests of the DP welded joints were conducted under a constant amplitude strain control mode. The welded joints experienced a fatigue life reduction with respect to the DP980 steel of $\sim 16 \%$ at strain amplitudes of $0.2,0.3$, and $0.4 \%$. For strain amplitudes larger than $0.6 \%$, the fatigue life of the welded joint was reduced by $39 \%$. Weld thermal cycles combined with metallography analysis indicated that a tempered process of the martensite during the welding was responsible for the soft-zone formation and the poor fatigue response.
\end{abstract}

Keywords: DP980 steel sheet; low cycle fatigue; gas metal arc welding; heat affected zone; tempered martensite

\section{Introduction}

Advanced High-Strength Steels (AHSS) is a group of steels widely used by the automotive industry because of their superior mechanical properties obtained by well-controlled thermomechanical processes and the resulting microstructures. Dual-Phase (DP) steels are part of this group. DP steel's microstructure consists of a ferrite matrix $(\alpha)$ with dispersed martensite islands [1-3]. The adequate control in the martensite formation, morphology, and distribution can improve the mechanical strength, while the ductility is still sufficient for the sheet metal forming process [1,3-5]. Due to their high formability, the DP steels (and all the AHSS group) are suitable to fabricate lighter components with smaller thickness, reducing the final weight of the automotive body structure $[4,6]$. This weight reduction results in enhanced fuel efficiency with less exhaust emissions and allows a larger flexibility and the customization in the vehicle design process [1].

The automotive industry requires electric arc welding processes to join several components of the car body structures, and these joining processes produce a heat input that modifies the distribution and morphology of the martensite and ferrite grain size in the DP steels. Thus, the final behavior and durability of the welded components are modified [7]. Gas Metal Arc Welding (GMAW) is a permanent joining process by electric arc and filler metal, which is applied on automotive body structures, where the Resistance Spot Welding (RSW) cannot be used, such as in butt joints [7,8]. The electric arc induces a Heat Affected Zone (HAZ) in the material region adjacent to the Fusion Zone (FZ) [7,9]. The HAZ can be further divided as a function of the weld thermal cycles induced by the electric arc 
into High- and Low-Temperature zones (HT and LT). The HT-HAZ reaches temperatures corresponding to the austenite region $(\gamma)$ in the Fe-C diagram. At this point, the original ferrite transforms to austenite, which, upon quenching at high cooling rates, transforms to martensite, increasing the content of this phase. Meanwhile, at the LT-HAZ, the reached temperature is lower than the $(\alpha+\gamma)$ region; thus, the cooling rates are slower [10]. This contributes to the tempering of the existing martensite, decreasing the mechanical strength and hardness. A softened zone is formed, which acts as a preferential failure zone.

The modification of the mechanical properties and microstructural conditions in the DP welded joints represent an important issue in the industry which has been investigated elsewhere. Ramazani et- al. [7] characterized the macroscopic mechanical properties for GMAW joints in DP600. The hardness results showed a soft zone located at the LT-HAZ, and where the final fracture took place. They explained that the soft zone was produced by the coarsening of the ferrite grain and the tempering of preexisting martensite. Kuril et al. [11] also reported the tempering of the martensite at the softened zone for DP600 steel when it was subjected to keyhole plasma arc welding. The failure also occurred at the softened zone. Most of the literature results are limited to evaluating DP welded joints subjected to exclusively tensile loading without analyzing the behavior under cyclic loading schemes. Ahiale and Oh [8] analyzed the behavior of GMAW joints of DP steels under cyclic loading (stress ratio $R=0.1$ ). They compared the behavior of DP440 and DP590 steels under conventional fatigue tests ( $S-N$ curves). In addition, they analyzed the effect of the fatigue stress concentration induced by the weld reinforcement. However, this study was focused only on cyclic loads which did not exceed the yield strength. The results indicated that the softened zone induced by the tempered martensite was not the critical failure zone if the weld reinforced was present. On the other hand, the softened zone remained the critical failure zone when the weld bead was removed (smooth specimen). Furthermore, for the smooth specimen, the comparison between DP steels showed a higher fatigue life for DP590, which has a higher hardness. He et al. [12] assessed the microstructure of the welded joints and its effect on the tensile and conventional fatigue properties for different combinations of similar/dissimilar materials with different thicknesses. Their research found a greater severity of the softened zone for the DP1000 steel than for the DP800 steel. The hardness drop for DP1000 steel on the softened zone was 20\%, and for the DP800 steel the drop was of $8 \%$ when compared to the base material. Fatigue failure in all the welded joints occurred at the fusion zone due to inhomogeneities and defects induced during welding because they report oxide particles and concavities in the welded joints, which promoted crack initiation. In another work, laser welding joints for DP600 and DP980 were evaluated under conventional fatigue tests (stress ratio $R=0.1$ ) by Farabi et al. [13]. They reported a softened zone in the LT-HAZ. The results indicated that the influence of the softened zone on the fatigue life was more severe for the DP980 than for DP600 welded joints. They attributed this to the larger martensite content in the DP980 steel. Xia et al. [14] evaluated the laser welded joints of different DP steels and reported that the degree of softening due to heat input was proportional to the martensite content. Unfortunately, there is a lack of studies in the literature where DP welded joints are subjected to low cycle fatigue (LCF) conditions, and the soft zone is evaluated under these service conditions. Awareness of the softened zone induced in electric arc welded joints of DP steels and the related loss of mechanical strength under monotonic loading condition is of relevance for automotive body design. Furthermore, the fatigue response of the softened zone under LCF conditions is extremely relevant. For these reasons, this research work focuses on the analysis of GMAW welded joints of DP980 steel subjected to monotonic and cyclic loading conditions which generates cyclic plastic strains. The welded joints were evaluated by microstructural and hardness analysis. Fatigue behavior is also reported in terms of cyclic strain hysteresis loops, cyclic stress-strain curves, variable stress amplitude response during the cyclic loads, strain-life, and stress-life curves. 


\section{Materials and Methods}

\subsection{Base Material and Welded Joints}

DP980 steel sheets with dimensions of $280 \mathrm{~mm} \times 140 \mathrm{~mm} \times 1.60 \mathrm{~mm}$ were joined using a standard flare V-groove configuration in agreement with the standard AWS D9.1 [15], as showed in Figure 1a. Table 1 presents the chemical composition for the DP980 steel sheet and Spoolarc 120 filler metal (The ESAB group Inc., Hanover, PA, USA), respectively. To obtain the joints, the GMAW process was performed using a Miller ${ }^{\circledR}$ Dimension 652 power source (Miller Electric Mfg. LLC., Appleton, WI, USA) equipped with a control panel, wire feeder, and a welding torch. A semiautomatic device implemented by the working group (CIITEC, Mexico City, Mexico) was used to keep a constant welding speed and a straight path. Shielding gas consisting of a mixture of $20 \% \mathrm{CO}_{2}$ and $80 \% \mathrm{Ar}$ (volume fraction) was used at a flow rate of $0.03 \mathrm{~m}^{3} \cdot \mathrm{min}^{-1}$. The used welding parameters were a $V$ voltage of $20 \mathrm{~V}, \mathrm{I}$ current of $90 \mathrm{~A}, v$ travel speed of $5 \mathrm{~mm} \cdot \mathrm{s}^{-1}$ and a pre-heating temperature of $240{ }^{\circ} \mathrm{C}$. According to Equation (1), a heat input $Q$ of $302 \mathrm{~J} \cdot \mathrm{mm}^{-1}$ was determined considering a thermal efficiency $\eta$ of $84 \%$ for the GMAW process [16]. In addition, K-type thermocouples were placed on the welding plate (at distances of $4 \mathrm{~mm}$ and $5.5 \mathrm{~mm}$ from the weld center) to obtain temperature measurements in the HAZ. Figure 1b shows the experimental setup for the welding process and the K-type thermocouples attached to the plate, which were connected to a data acquisition card from National Instruments model 913. An insulator ceramic was used to protect the thermocouple sensors from the electric arc.

$$
Q=\eta \frac{V I}{v}
$$
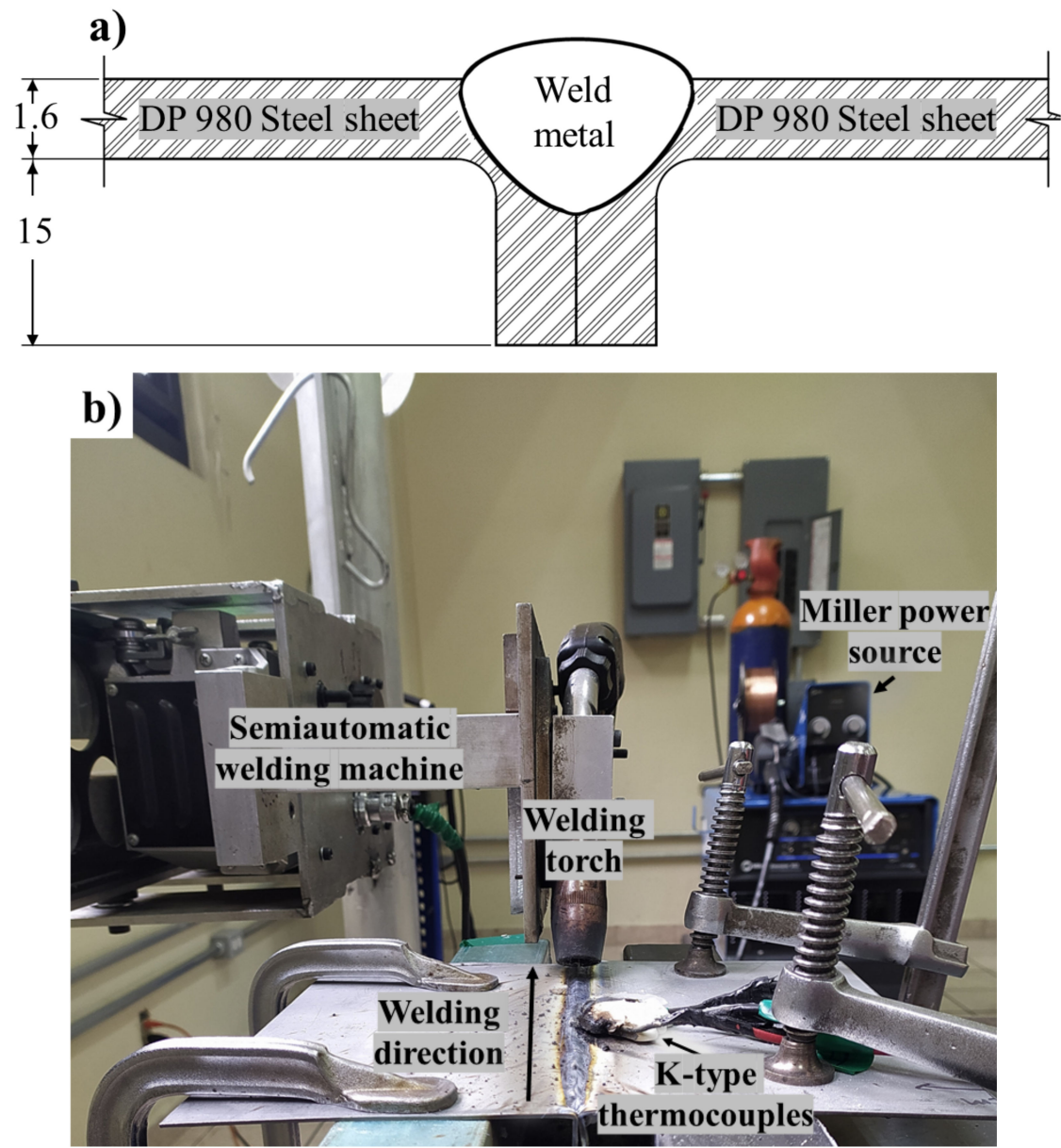

Figure 1. Configuration for welding process of DP980 steel sheets (a) Schematic draw for the joint geometry with a standard flare V-groove preparation, dimensions are in $\mathrm{mm}$. (b) Experimental setup. 
Table 1. Chemical composition of the DP980 and filler metal (wt. \%).

\begin{tabular}{ccccccccccccccccc}
\hline Material & C & Mn & Si & P & S & Cr & Ni & Mo & Al & Cu & Ti & Zr & Fe \\
\hline DP980* & 0.130 & 2.260 & 0.420 & 0.012 & 0.009 & 0.950 & 0.021 & 0.110 & - & - & - & - & 96.087 \\
Spoolarc 120** & 0.070 & 1.690 & 0.350 & 0.004 & 0.004 & 0.270 & 2.490 & 0.510 & 0.005 & 0.030 & 0.018 & 0.002 & 94.557 \\
\hline
\end{tabular}

* Determined by optical emission spectrometry. ${ }^{* *}$ As data sheet reported [17].

The DP980 welded joints were metallography characterized in the longitudinal to rolling (L), long transverse (LT), and short transverse (ST) material directions. After the GMAW process, transversal welding bead samples were saw-cut. The samples were grounded with a different granulometry of $\mathrm{SiC}$ paper and polished with a $1 \mu \mathrm{m}$ diamond paste. After polishing, the surface was etched using a reagent solution of $3 \%$ of $\mathrm{HNO}_{3}$ and $97 \%$ of Ethanol (Nital 3). Optical microscopy (Nikon metrology Inc., Tokyo, Japan) was used to reveal the final microstructure. The ferrite content was determined using a Fischer FERITSCOPE ${ }^{\circledR}$ FMP30 device (Helmut Fischer GmbH, Sindelfingen, Germany), and this allowed the determination of the martensite content.

\subsection{Experimental Tests}

The hardness in the DP980 and welded joints were determined with a Vickers microindentation test (Buehler Ltd., Lake Bluff, IL, USA). The hardness evaluation was in concordance with the standard ASTM-E92 [18]. The load used was $4.905 \mathrm{~N}(0.5 \mathrm{~kg})$, and the dwell time was $15 \mathrm{~s}$. Microhardness measurements in the DP980 steel were obtained in the rolling (L), transverse to rolling (TL), and short transverse (ST) directions. In the welded joints, Vickers microhardness measurements were performed in the transversal section perpendicular to the welded joint. A linear scanning path was followed to obtain the hardness measurement of all the zones produced by the welding process. The separation between each indentation was $0.5 \mathrm{~mm}$.

A servo hydraulic MTS-Landmark (MTS System Headquarters, Eden Prairie, MN, USA) equipped with a $100 \mathrm{kN}$ load cell, an extensometer, and a data acquisition system were employed to conduct monotonic tensile and LCF tests. The monotonic tensile tests were performed according to the standard ASTM-E8 [19]. The crosshead displacement was set to $1 \mathrm{~mm} \cdot \mathrm{min}^{-1}$. Standard dog-bone specimens were used for the tensile test. Figure 2a shows the schematic representation of the welded joint and the specimen cut. Figure $2 b$ shows the corresponding dimensions for the tensile dog-bone specimens. Dog-bone specimens were tested for each material, and the engineering stress-strain $(\sigma-\varepsilon)$ curves were reported and used to determine the corresponding mechanical properties. In addition, true stress-strain $(\widetilde{\sigma}-\widetilde{\varepsilon})$ behaviors were computed from the obtained engineering data from the yield point until the initiation of necking, applying Equations (2) and (3).

$$
\begin{aligned}
& \widetilde{\sigma}=\sigma(1+\varepsilon) \\
& \widetilde{\varepsilon}=\ln (1+\varepsilon)
\end{aligned}
$$

The Ramberg-Osgood model is shown in Equation (4) and was used to fit the true stress-strain data. The fit allowed the determination of the strength coefficient $K$ and strain hardening exponent $n$. For additional $\widetilde{\sigma}-\widetilde{\varepsilon}$ data, the Hollomon constitutive model (Equation (5)) was used to obtain extrapolated data until the fracture point.

$$
\begin{gathered}
\widetilde{\varepsilon}=\frac{\widetilde{\sigma}}{E}+\left(\frac{\widetilde{\sigma}}{K}\right)^{\frac{1}{n}} \\
\sigma=K \cdot\left(\varepsilon_{p}\right)^{n}
\end{gathered}
$$



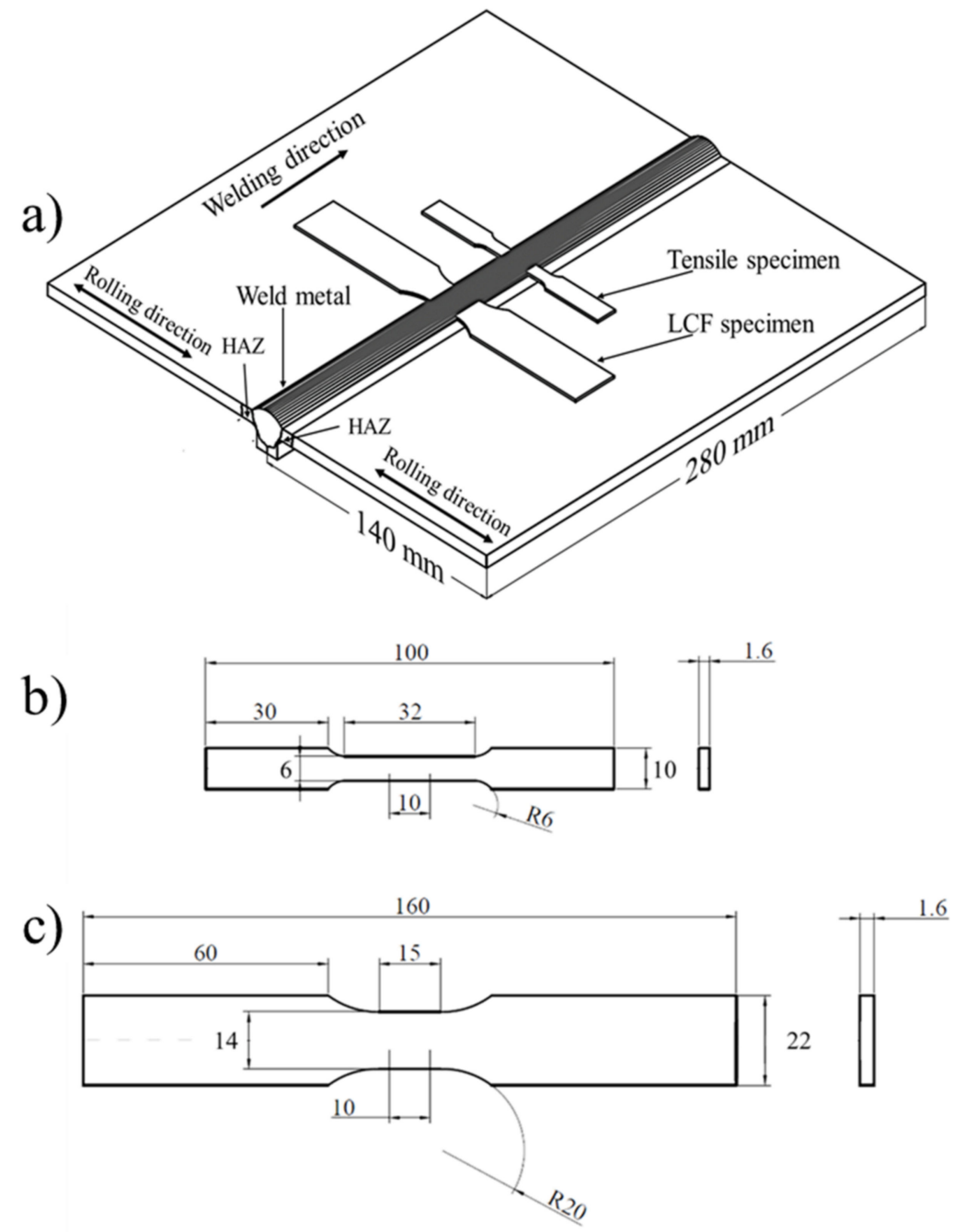

Figure 2. (a) Schematic representation of welded joint and the specimens located. (b) Specimen geometry used for tensile tests and (c) for LCF tests. All dimensions are in mm.

In the case of LCF, the tests were performed following the recommendations established in the standard ISO-12106 [3]. The LCF tests were conducted with a constant amplitude strain, a strain ratio of $R=-1$, and a triangular waveform for the applied strain cycles. Table 2 presents the LCF test program used for the DP980 and welded joints, which consists of five different strain amplitudes $\varepsilon_{a}$ and test frequencies. Material availability limited the test matrix to 10 samples per each material. The testing strain amplitudes selected were such that during the first cycle, the induced stress exceeds the yield strength of the DP980 steel, so all of them are in the plastic strain field. The strain amplitude $\varepsilon_{a}=0.008$ was set as the maximum because at higher strain values, and with $R=-1$, the specimen undergoes buckling before the complete fracture of the tested sample. Although, an anti-buckling system was used for all the tested strain amplitudes as recommended in the standard ISO 12106. A constant strain rate $\dot{\varepsilon}$ of $0.016 \mathrm{~s}^{-1}$ was used for the entire test program. Thus, it was necessary to adjust the frequency $f$ for each strain amplitude $\left(\varepsilon_{a}\right)$. The relationship between strain amplitude, strain rate, and frequency used to set the constant $\dot{\varepsilon}$ is shown in Equation (6). Figure 2c shows the geometry and dimensions of the dog-bone specimen used for this LCF test.

$$
f=\frac{\dot{\varepsilon}}{4 \varepsilon_{a}}
$$


Table 2. LCF experimental test program.

\begin{tabular}{cccc}
\hline \multirow{2}{*}{ Strain Amplitude, $\boldsymbol{\varepsilon}_{\boldsymbol{a}}(\mathbf{\%})$} & Test Frequency, $\boldsymbol{f} \mathbf{( H z )}$ & \multicolumn{2}{c}{ Tested Samples } \\
\cline { 3 - 4 } & & DP980 Steel Sheet & Welded Joints \\
\hline 0.2 & 2 & 1 & 3 \\
0.3 & 1.333 & 2 & 2 \\
0.4 & 1 & 3 & 1 \\
0.6 & 0.667 & 2 & 3 \\
0.8 & 0.5 & 2 & 1 \\
\hline
\end{tabular}

The data acquisition system in the MTS machine allows recording of the strain, applied force as a function of the testing time, and the number of cycles to failure $N_{f}$. The monitoring of these parameters was used to determine the total strain amplitude $\varepsilon_{t}$, plastic strain amplitude $\varepsilon_{p}$, cyclic elastic modulus $E_{c}$, and total stress amplitude $\sigma_{a}$. Stable stress-strain hysteresis loops were plotted for each specimen at every strain amplitude. From hysteresis loops, the cyclic elastic modulus $E_{c}$ was determined according to the procedure defined in the standard ISO-12106 [20]. This value was used to estimate the elastic strain amplitude $\varepsilon_{e a}$ based on Hooke's law. The cyclic stress-strain behavior of welded joints and DP980 steel sheet was determined using the stable elastic strain and stress amplitudes. From the plot, cyclic yield strength $\sigma_{y^{\prime}}$ was estimated at $0.2 \%$ strain offset. The cyclic elastic modulus $E_{c}$ was approximated to the Ramberg-Osgood Equation (7) to obtain the cyclic strength coefficient $K^{\prime}$ and cyclic strain hardening exponent $n^{\prime}$.

$$
\varepsilon_{a}=\left(\frac{\sigma_{a}}{E_{c}}\right)+\left(\frac{\sigma_{a}}{K^{\prime}}\right)^{1 / n^{\prime}}
$$

The plastic strain amplitude $\varepsilon_{p a}$ was determined to be the difference between the total strain $\varepsilon_{a}$ and the elastic strain $\varepsilon_{e a}$ amplitudes determined previously. The evolution of the $\varepsilon_{e a}, \varepsilon_{p a}$, and $\varepsilon_{a}$ versus $2 N_{f}$ were determined from the experimental LCF results. The fatigue ductility coefficient $\varepsilon_{f}^{\prime}$ and the fatigue ductility exponent $c$ were obtained by means of a least square method fitting to the plastic component of the Coffin-Manson Equation (8). The determined coefficients were applied to the Coffin-Manson equation and the curves of elastic, plastic, and total strain versus the number of reversals to failure were plotted. In order to track the hardening and softening behavior in terms of stress response at different strain amplitudes during the cyclic loading of welded joints and the DP980 steel sheet, the stress amplitude response vs. the number of cycle curves were plotted. The fatigue strength coefficient $\sigma_{f}^{\prime}$ and the fatigue strength exponent $b$ were determined by the least square method, considering the stable stress amplitude and $2 \mathrm{Nf}$ and fitted to Basquin's Equation (9). This data was plotted to $S-N$ curves.

After LCF tests, surface fracture was evaluated using a JEOL JSM-6300 Scanning Electron Microscope (SEM, JEOL Ltd., Tokyo, Japan), equipped with SEI (Secondary Electron Image) with an acceleration voltage of $20 \mathrm{keV}$.

$$
\begin{gathered}
\varepsilon_{a}=\varepsilon_{e a}+\varepsilon_{p a}=\frac{\sigma_{f}^{\prime}}{E}\left(2 N_{f}\right)^{b}+\varepsilon_{f}^{\prime}\left(2 N_{f}\right)^{c} \\
\sigma_{a}=\sigma_{f}^{\prime}\left(2 N_{f}\right)^{b}
\end{gathered}
$$

\section{Results and Discussion}

\subsection{Base Material and Welded Joints}

The microstructure of the DP980 steel sheet is presented in Figure 3. It exhibits the typical fine islands of martensite homogenously dispersed in the ferrite matrix, as reported elsewhere [21], which corresponds to an intermediate quenching heat treatment. The average ferrite grain size was about $5 \mu \mathrm{m}$ for the L and LT directions. Meanwhile, for the ST direction grain size was close to $6.5 \mu \mathrm{m}$. These values, which were determined by the 
application of the circle interception method as described in the standard ASTM-E112 [22] guidelines, are within the range of similar DP steels reported in the literature $[21,23,24]$. Differences in the grain morphology between the L and LT directions are not strongly marked because of the fine martensite islands. The L and LT metallographic images show slightly elongated grains, when compared to the ST directions, which was attributed to the rolling process which deforms the grains. A martensite content of $38 \%$ was obtained by means of ferrite measurements (Fischer FERITSCOPE ${ }^{\circledR}$ FMP30 device, Helmut Fischer $\mathrm{GmbH}$, Sindelfingen, Germany).
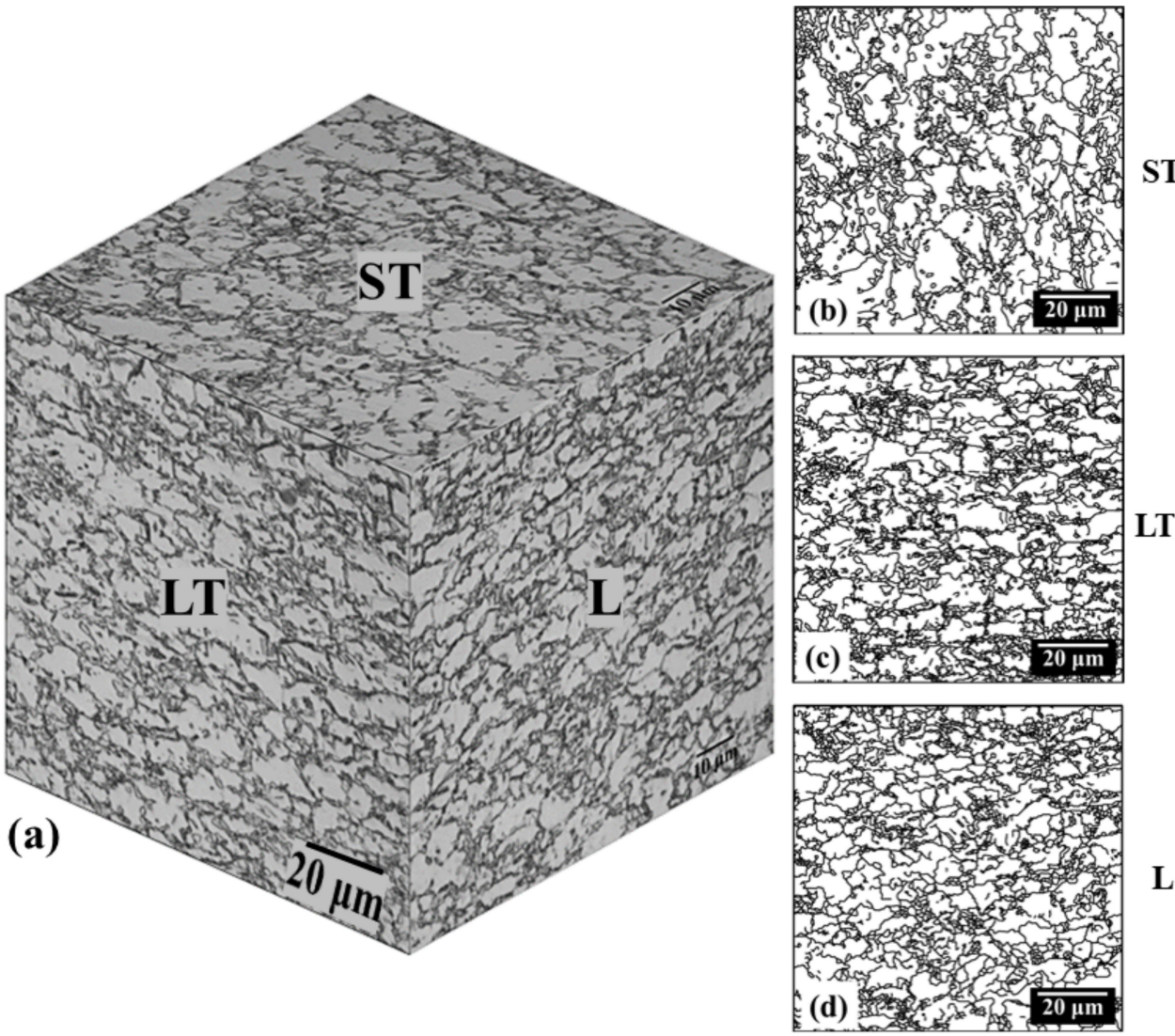

Figure 3. Microstructure of the DP980 steel sheet. (a) Three-dimensional view, (b) short transverse direction, (c) long transverse direction and (d) corresponds to the longitudinal to rolling direction.

The welded joint macrographic picture is presented in Figure 4. By visual inspection, no defects were detected in the welded joint such as porosity, microcracking, undercut, or a lack of fusion. Thus, a good quality was obtained for the welded joints appearance. It can be observed that the FZ presents columnar grains which nucleate in the base metal and grow following the electric arc direction, as a result of the heat transfer phenomenon. In addition, the microstructure of the HT-HAZ, LT-HAZ, and the base metal were identified. Figure 5a shows that the FZ exhibits needle-type martensite, which was promoted because, at this zone, the melting temperature $\left(\sim 1538^{\circ} \mathrm{C}\right)$ was reached, and a fast-cooling rate was induced. Figure $5 \mathrm{~b}$ shows the differences in the martensite morphology for the HT-HAZ with respect to the previous FZ. The presence of lath martensite is evident in the HT-HAZ (Figure 5c), where the martensite content rose $54 \%$ due to a peak temperature of $913{ }^{\circ} \mathrm{C}$ (higher than the $A c_{3} \sim 800{ }^{\circ} \mathrm{C}$ ) during the welding, which was measured by the K-type thermocouple placed on the surface of the plate at $4 \mathrm{~mm}$ from the weld center. When this temperature was reached, the ferrite on the DP980 steel matrix was transformed to austenite and then quenched, forming lath-type martensite [10]. The cooling rate determined at this point was of $21^{\circ} \mathrm{C} \cdot \mathrm{s}^{-1}$. Regarding the LT-HAZ, tempered martensite can be observed (Figure 5d). Tempering preexisting martensite of the DP980 steel is promoted when the peak 
temperature is lower than $A c_{1}$ temperature $\left(\sim 720^{\circ} \mathrm{C}\right)$ [10]. The measured peak temperature by the K-type thermocouple placed within this zone, at $5.5 \mathrm{~mm}$ from the weld center, was $697^{\circ} \mathrm{C}$, and the cooling rate was of $7^{\circ} \mathrm{C} \cdot \mathrm{s}^{-1}$. In Figure 6 , the experimental cooling rates obtained from the weld thermal cycles measured were drawn on the time-temperaturetransformation (TTT) diagram for DP1000 steel, this verified that the HT-HAZ presented lath type martensite and LT-HAZ presented tempered martensite. Despite the larger content of martensite in the LT-HAZ (60\%) with respect to the content in the HT-HAZ (54\%), the LT-HAZ has a lower strength and hardness due to the type of martensite contained within this zone, which was tempered.

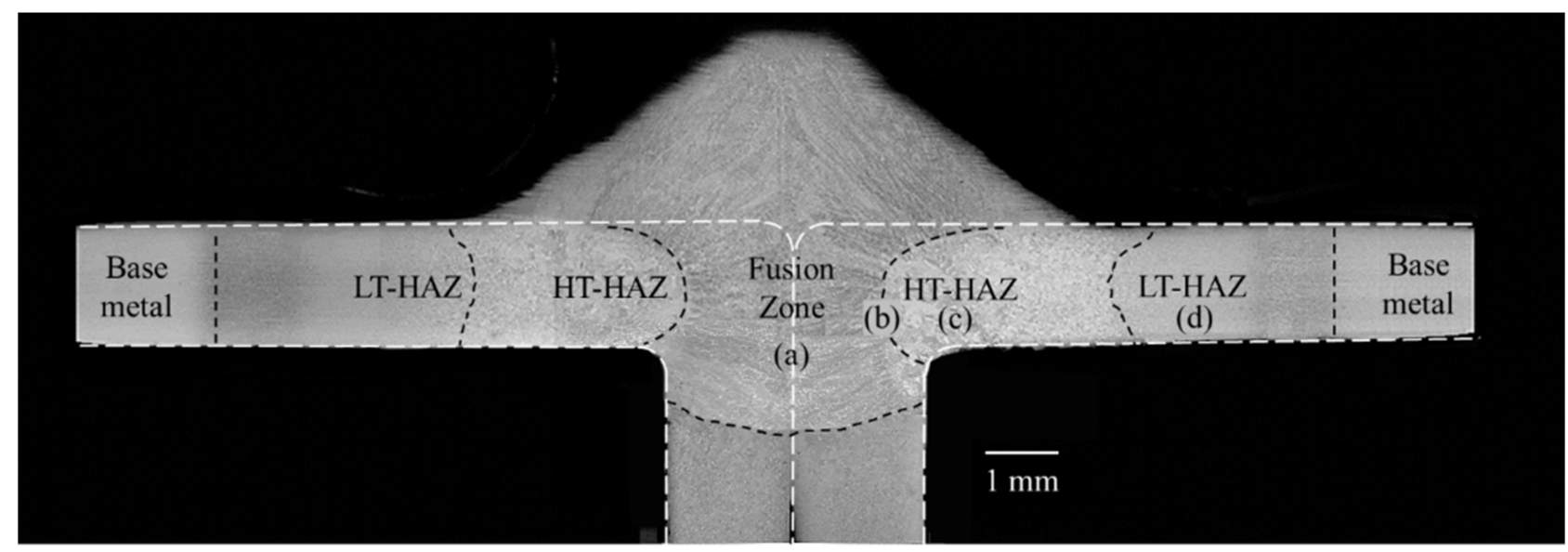

Figure 4. Transversal macrographic view of the GMAW joint. Complete welding penetration in the FZ is observed. The different welding zones are marked in the view. (a) Fusion zone, (b) fusion line, (c) high temperature heat affected zone and (d) low-temperature heat affected zone.
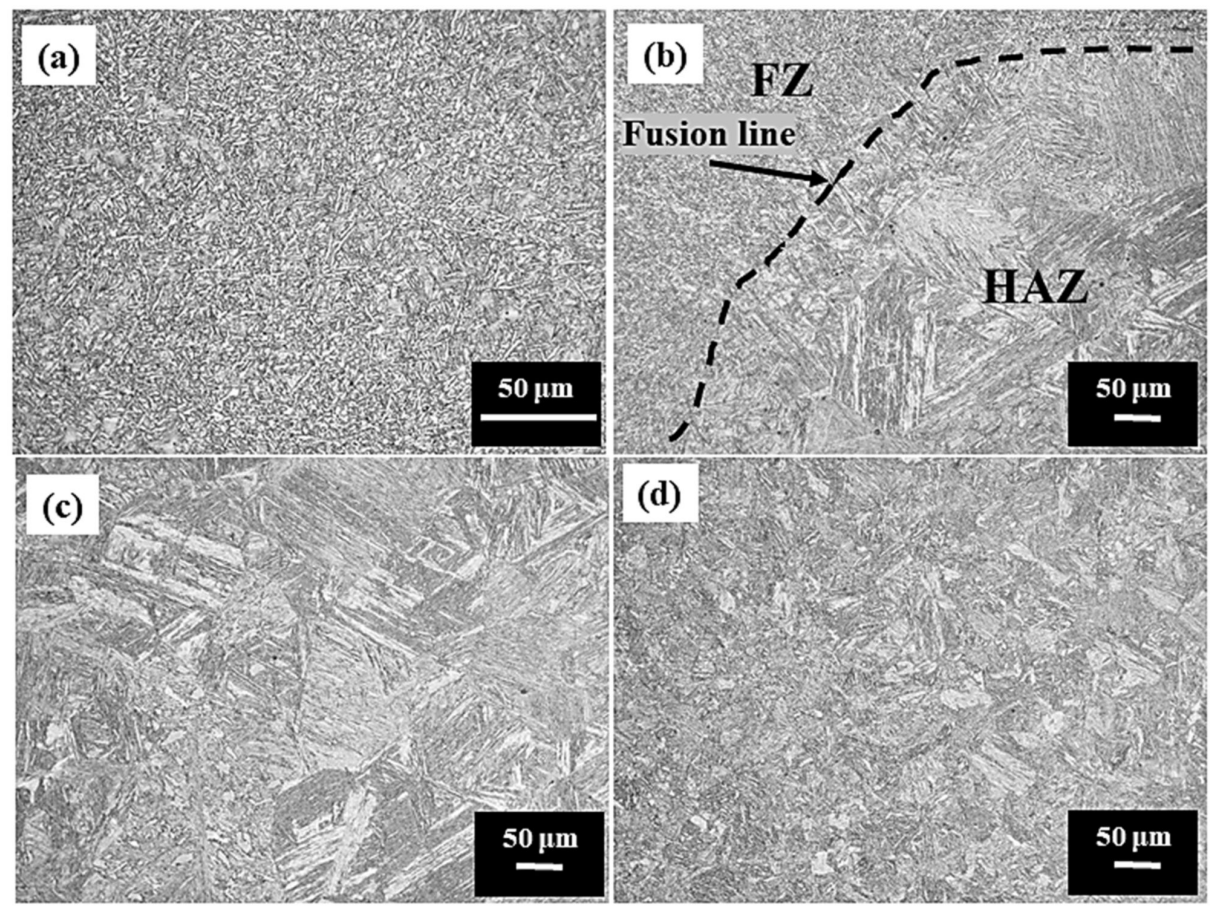

Figure 5. Different microstructures of the welding zones: (a) FZ, (b) transition of the FZ to the HAZ (fusion line can be observed), (c) HT-HAZ and (d) LT-HAZ. 


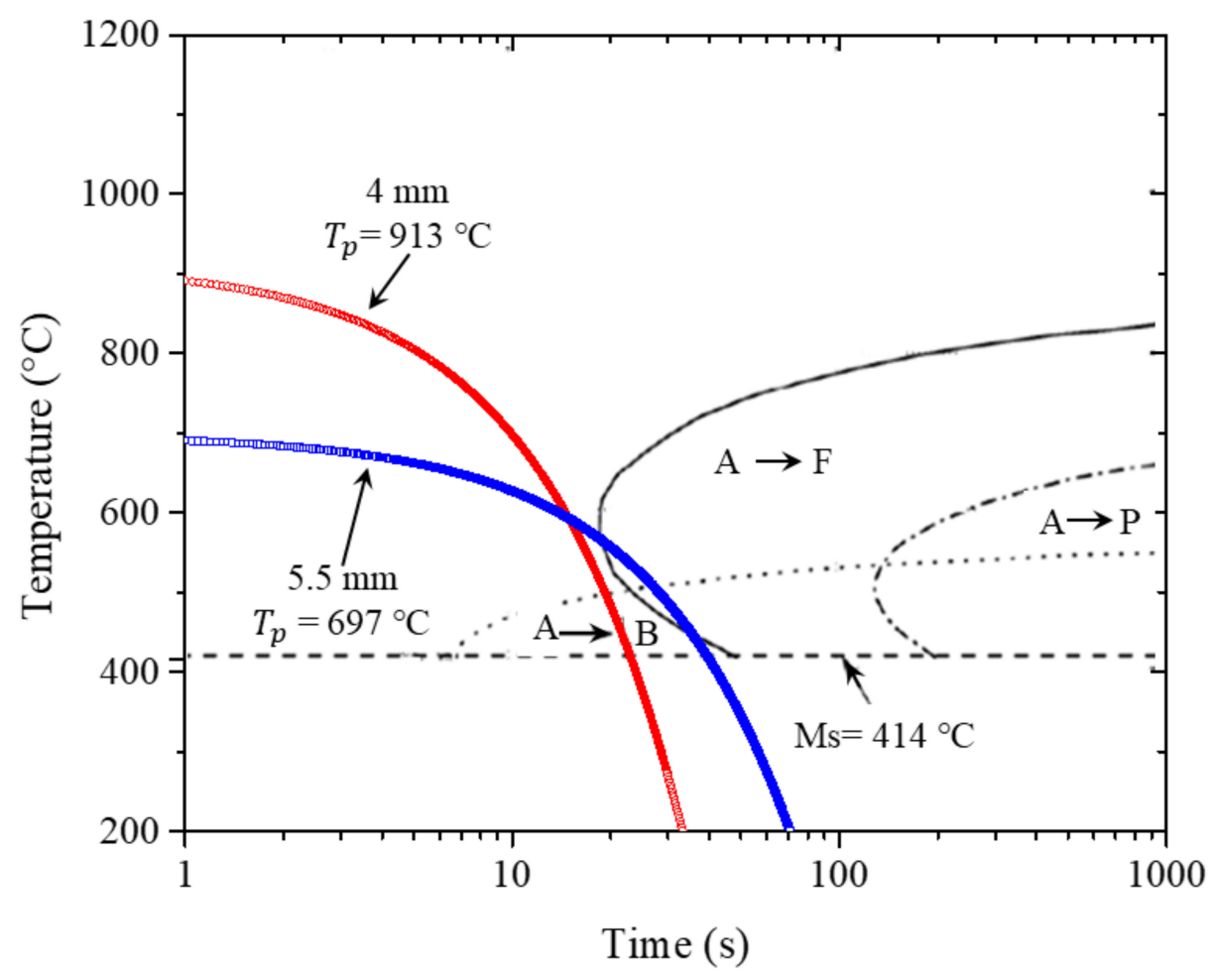

Figure 6. Experimental cooling rates for the LT-HAZ and HT-HAZ of the DP980 welded joints and its corresponding time-temperature-transformation diagram [10].

\subsection{Mechanical Properties}

The average results obtained from Vickers microhardness measurements on DP980 steel sheet for the longitudinal (L) direction was $313 \mathrm{HV0.5}$, in the long transverse (LT) direction was 316 HV0.5, and in the short transverse (ST) direction was 315 HV0.5. These results are similar to reported values in the literature for DP steel grade, in the range of 300-320 HV0.5 [8-10]. No significant differences were found in the hardness between the rolling directions, which indicated the homogenous distribution of the martensite islands in the ferrite matrix. This distribution can result from a continuous annealing process in the intercritical regime. This process consists of holding the material in the austenite-ferrite (intercritical) regime followed by a quenching plus a holding at temperatures slightly below the martensite start temperature, whereby the austenite fraction transforms into martensite [11].

The welded joint microhardness profile is presented in Figure 7. In the FZ, the microhardness measurements were above 320 HV0.5. Despite the low carbon content of the filler metal (0.07 wt. \%), the hardness of this zone was higher than the DP980 steel sheet, resulting from the presence of needle-type martensite, which was described in the previous section. In the HT-HAZ, the effect of lath-type martensite increased the microhardness to values up to $380 \mathrm{HV0.5}$. In contrast, in the LT-HAZ, the presence of tempered martensite reduced (compared to the DP980) the microhardness to values lower than $260 \mathrm{HV} 0.5$. This tendency of hardness variations is comparable to similar DP steel grades joined by fiber laser welding by Cui et al. [25], where they reported a hardness drop in the LT-HAZ down to $240 \mathrm{HV0.2}$. Xia et al. [14] found that, for diode laser welding of DP980 steel sheet, the minimum hardness in the LT-HAZ was 233 HV0.5. 


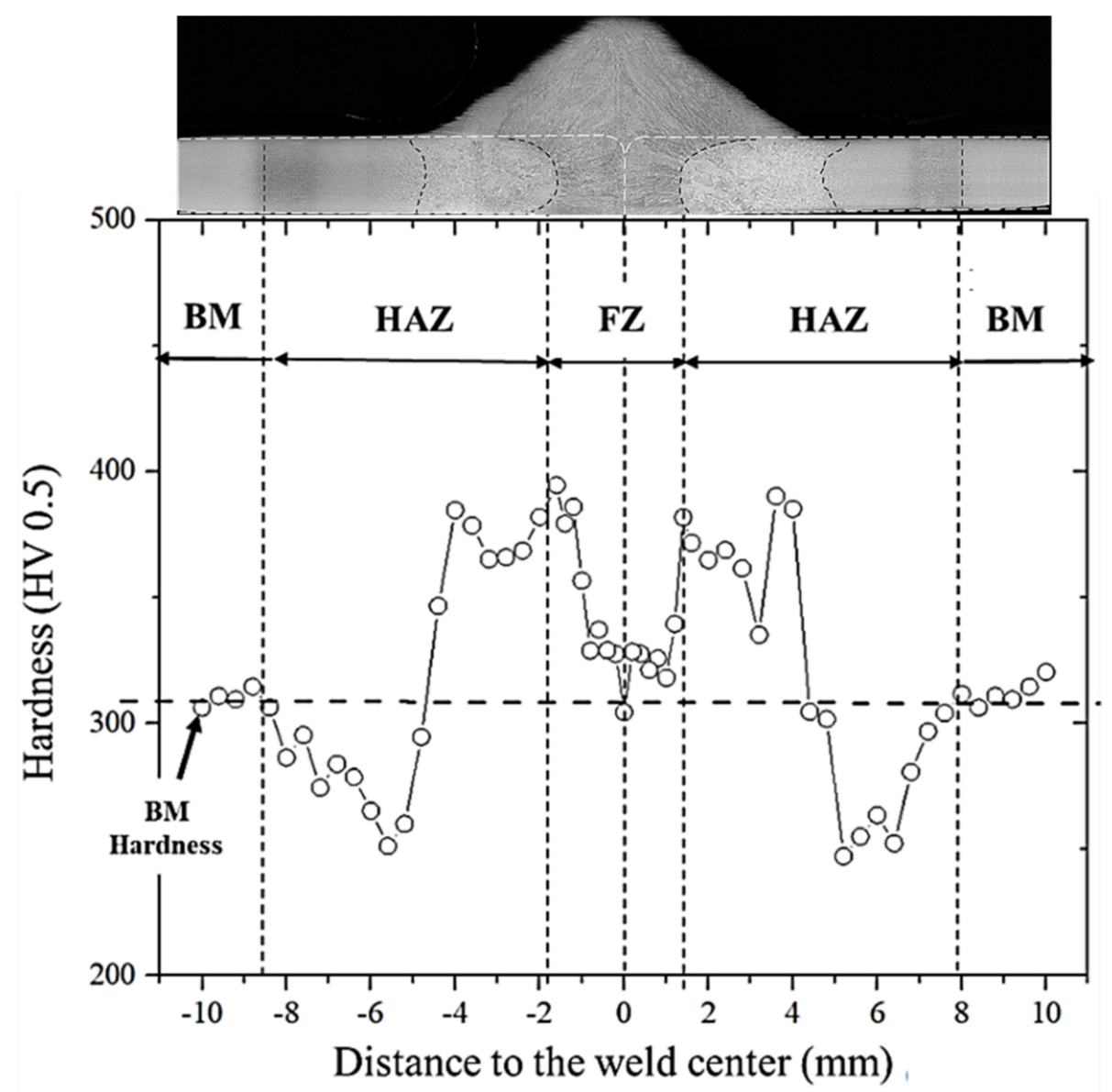

Figure 7. GMAW welded joints of DP980 steel in Vickers scale (HV0.5).

The stress-strain behavior is presented in Figure 8 for the DP980 steel sheet and welded joints, and their mechanical properties are summarized in Table 3. For the DP980, a ductile material behavior was observed, with an engineering fracture strain of around 0.15 . The mechanical properties were determined based on this stress-strain behavior according to the mechanical properties specified by the mill test certificate. Regarding the welded joints, the stress-strain behavior proved detrimental to the ductility since it was calculated as a reduction of about 75\% with respect to the base metal (DP980 steel sheet); therefore, the toughness also decreased. This diminution can be explained by a larger martensite content in the FZ, HT-HAZ, and the LT-HAZ compared to the DP980 steel sheet. As previously explained, each welding zone contains a characteristic type of martensite with different hardness values. Furthermore, a joint efficiency of $89 \%$ was obtained as a ratio of the welded joint strength to the DP980 steel sheet strength [26]. However, the failure took place at the softened region in the LT-HAZ, as shown in Figure 9, due to the presence of tempered martensite, which decreases the strength of the joint. This behavior has been previously reported in the literature $[10,13,14]$.

Table 3. Tensile mechanical properties.

\begin{tabular}{cccccccc}
\hline Material & $\sigma_{\mathbf{0 . 2} \%} \mathbf{( M P a )}$ & $\left.\sigma_{\boldsymbol{u}} \mathbf{( M P a}\right)$ & $\boldsymbol{E}(\mathbf{G P a})$ & $\varepsilon_{\max }(\mathbf{\%})$ & $\boldsymbol{K} \mathbf{( M P a})$ & $\boldsymbol{n}$ & Joint Efficiency (\%) \\
\hline DP980 & 699 & 1012 & 202 & 15 & 1389 & 0.0905 & - \\
Welded joints & 647 & 906 & 209 & 3.8 & 1388 & 0.113 & 89 \\
\hline
\end{tabular}




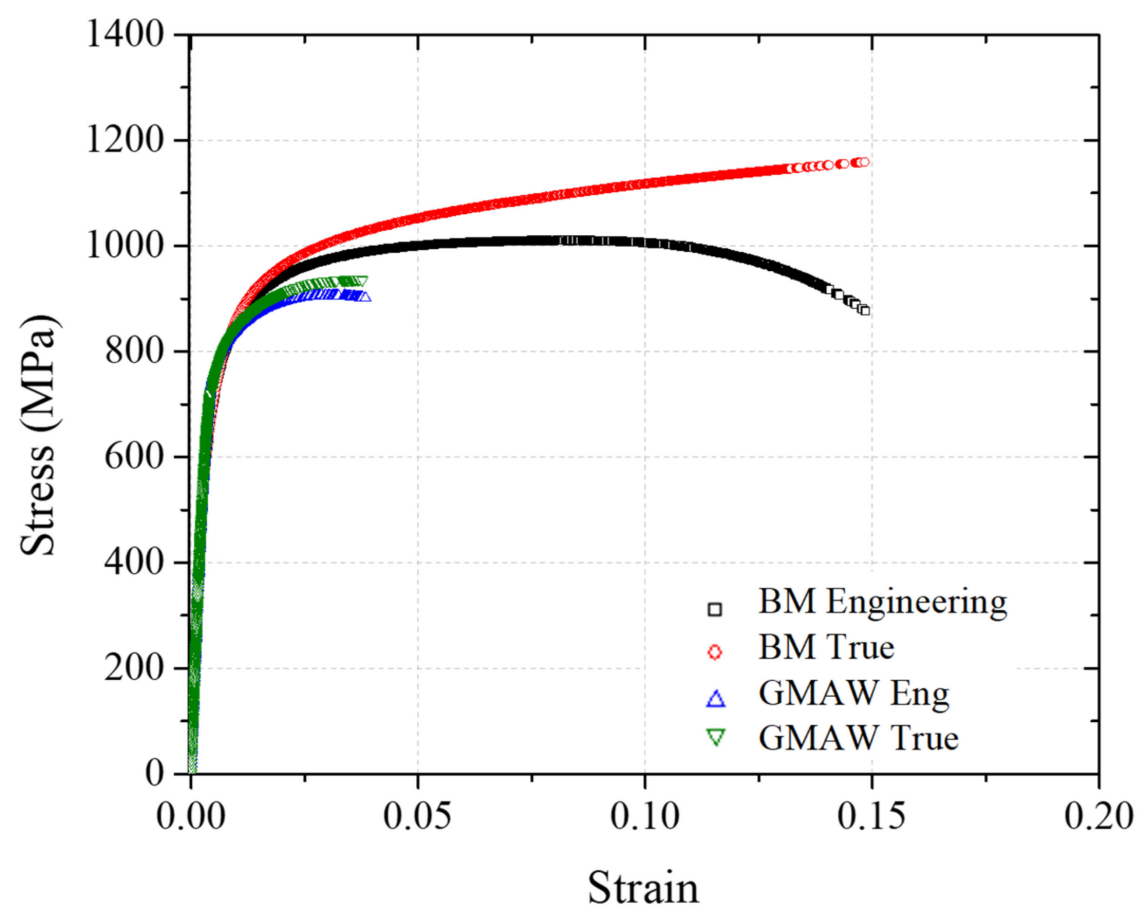

Figure 8. Tensile test stress-strain behavior for the base metal and welded joint of DP980 steel.

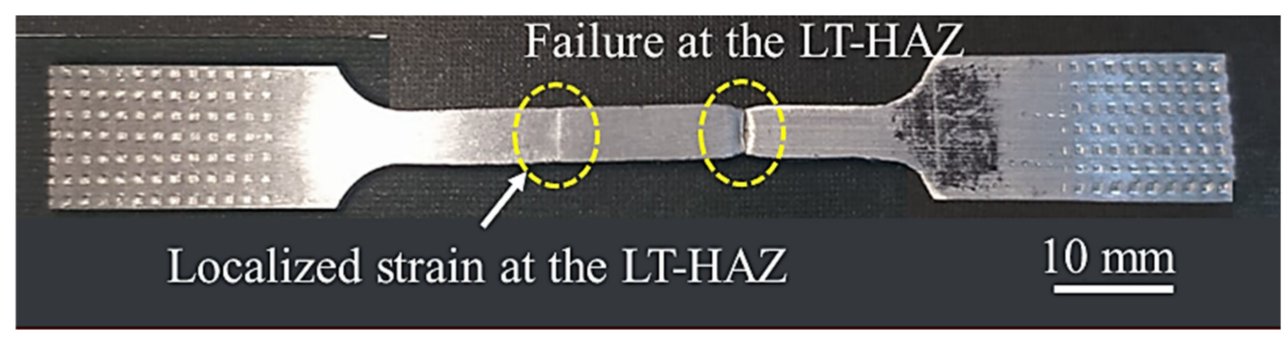

Figure 9. Dog-bone specimen of DP980 steel welded joint, failed at the soft region in the low temperature heat affected zone.

\subsection{Low Cycle Fatigue Tests}

The cyclic stable response in terms of true stress vs. strain for the DP980 steel sheet and welded joint is presented in Figure 10a,b. These hysteresis loops were obtained towards the middle of the LCF life, where the cyclic stress relaxation was overpassed. Comparing Figure 10a,b, the DP980 steel sheet exhibited a slender hysteresis loop for 0.006 and 0.008 strain amplitudes. Thus, the plastic strain was higher for the welded joint subjected to high strain amplitudes under cyclic stable response. In the case of strain amplitudes equal to 0.004 or smaller, both materials presented narrow hysteresis loops, with just a small difference between the DP980 and welded joint. The welded joint exhibited the slender hysteresis loops, which apparently indicated a smaller plastic strain than in the DP980 steel. However, the hysteresis loops correspond to the cyclic stable response of the materials and the welded joint could not present the smaller plastic strains. 


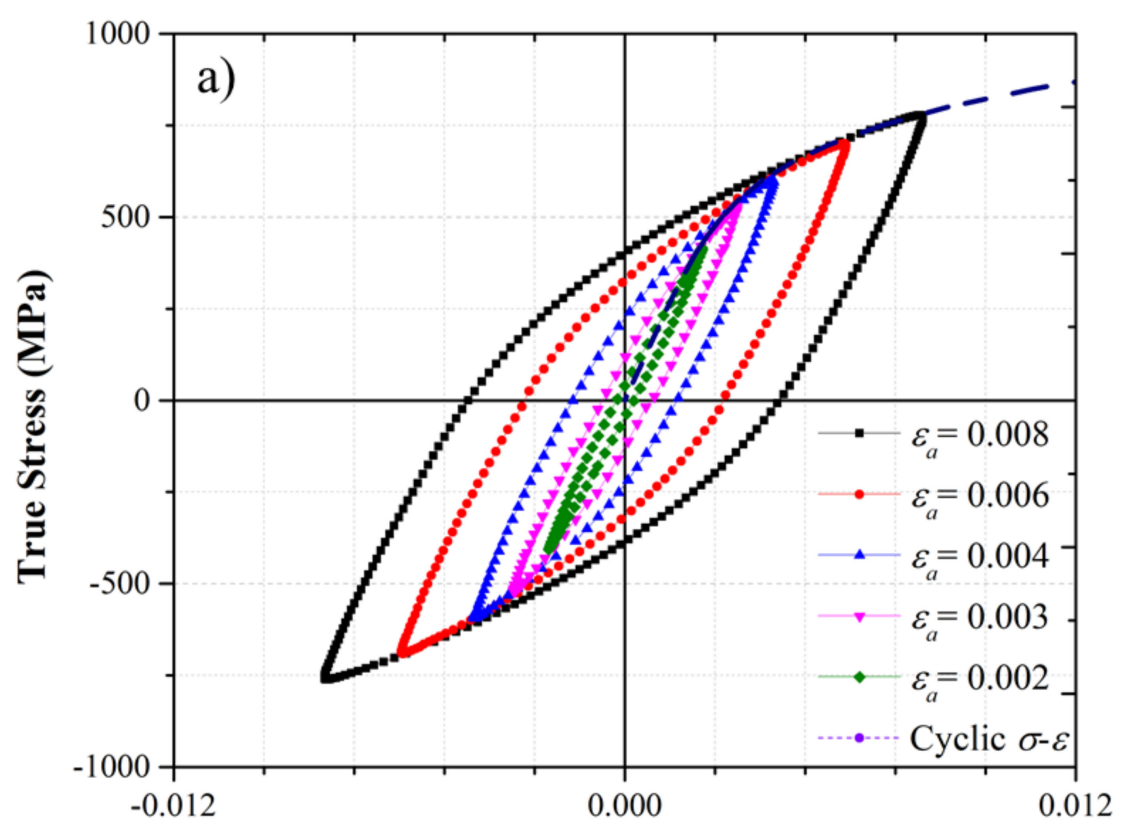

True Strain

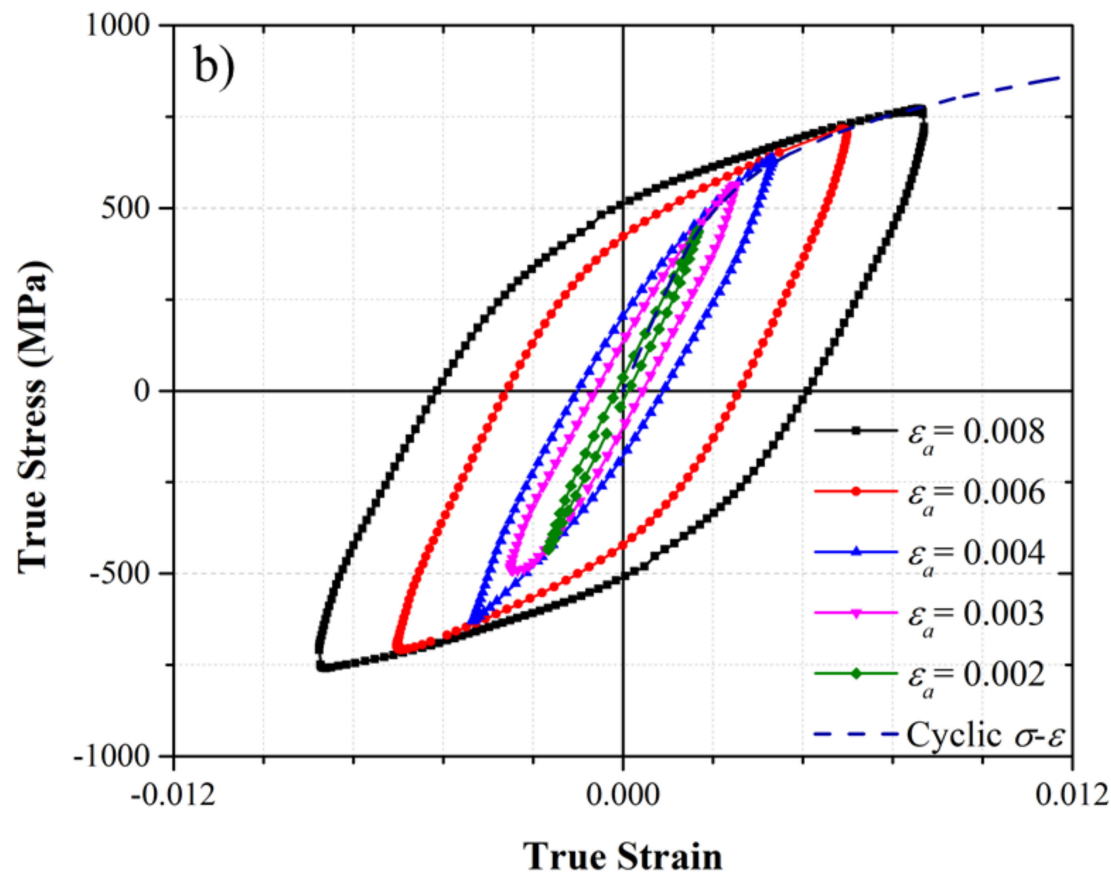

Figure 10. Hysteresis loops in LCF corresponding to (a) DP980 steel sheet and (b) welded joints.

The stable cyclic and tensile stress-strain curves for both materials (DP980 steel sheet and welded joints) are presented in Figure 11a,b. Cyclic mechanical properties are summarized in Table 4. Both materials presented a cyclic softening behavior with respect to the tensile one, as observed in the stress-strain curves by the experimental applied strain amplitudes. However, the softening effect severity is larger in the DP980 steel. The softening behavior for both materials can also be verified by comparison of cyclic and tensile yield strength. On average, for both materials, the cyclic yield strength reduced by $30 \%$ with respect to the tensile yield strength. Moreover, the cyclic stress-strain curves fitted to the Ramberg-Osgood equation indicated that for strain amplitudes larger than the applied experimentally, there is a mixed cyclic behavior with softening and hardening of both 
materials DP980 and welded joint. However, this mixed cyclic behavior must be verified by performing additional LCF tests with larger strain amplitudes.
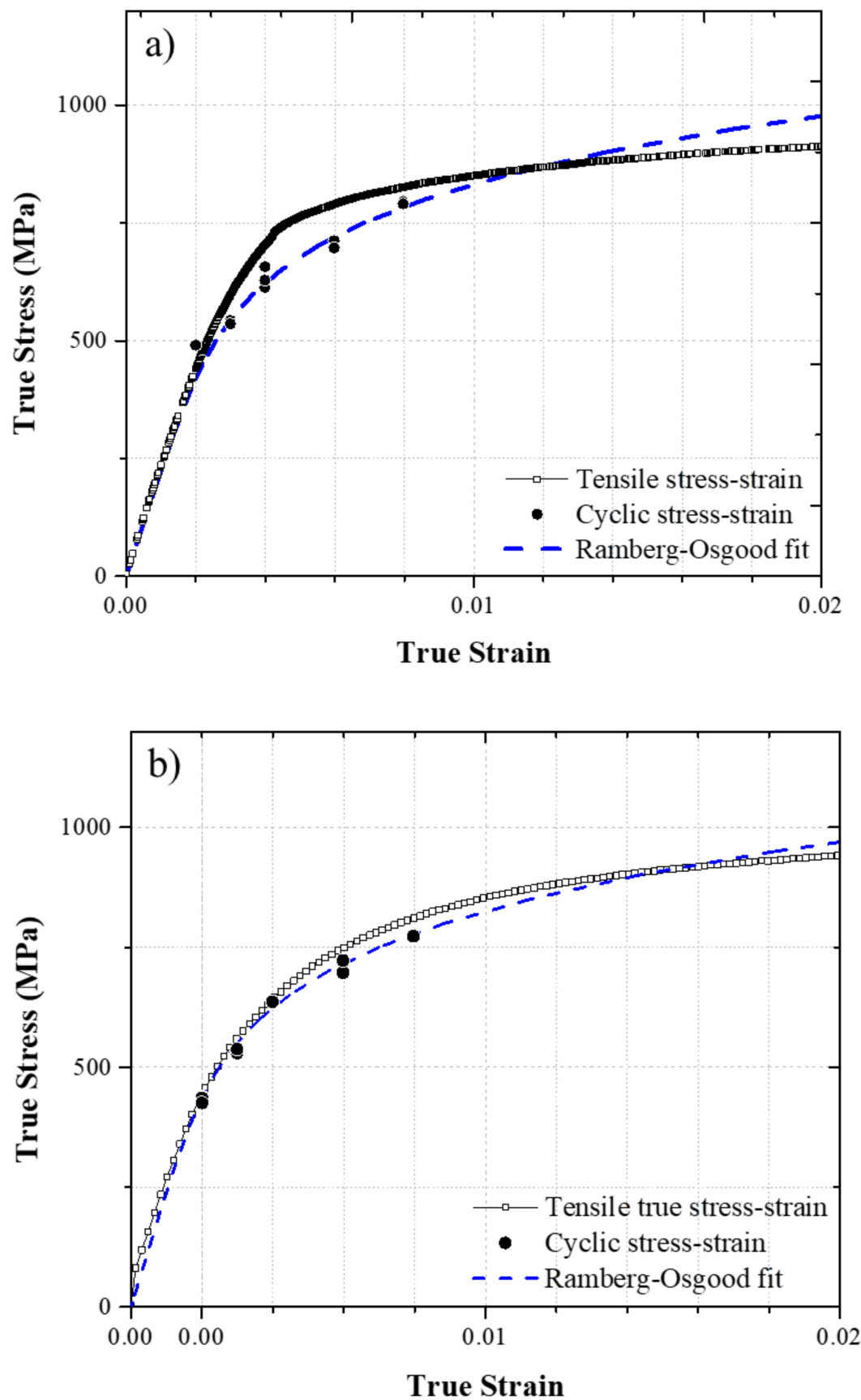

Figure 11. Cyclic stress-strain curves vs. monotonic tensile stress-strain curves. (a) DP980 steel sheet and (b) welded joints.

Table 4. Cyclic mechanical properties obtained from LCF.

\begin{tabular}{ccccc}
\hline Material & $\boldsymbol{E}(\mathrm{GPa})$ & $\sigma_{y^{\prime}}(\mathbf{M P a})$ & $\boldsymbol{K}^{\prime}$ & $\boldsymbol{n}^{\prime}$ \\
\hline DP980 & 234 & 490 & 2325 & 0.20 \\
Welded joints & 242 & 438 & 2064 & 0.18 \\
\hline
\end{tabular}

The strain-life curves are presented in Figure 12a for DP980 steel sheet and Figure 12b for the welded joint. Total, elastic, and plastic strain amplitudes are presented with the Coffin-Manson relationship and the determined coefficients for the elastic and plastic 
equation terms. Overall, a larger fatigue life was presented in the DP980 steel sheet than in the welded joint. The welded joint exhibited low scatter, and in some cases, the number of cycles to failure was almost identical at the corresponding strain amplitude, such as for $\varepsilon_{a}=0.006$ where two samples presented the complete fracture at almost the same $N_{f}$ ( 1900 cycles). Thus, the number of LFC test repetitions was regarded as adequate to analyze the fatigue response of the welded joint. Figure 12a,b showed that for the applied strain amplitudes, the welded joint presented the larger plastic strains. This result was not clear from the previously presented hysteresis loops in Figure 10a,b, but it can be explained based on the yield strength of the materials. The welded joint presented a lower yield strength, which can be associated with the tempered martensite in the LT-HAZ of the welded joint (Figure $5 \mathrm{~d}$ ) and is a result of the weld thermal cycles. A lower yield strength resulted in the plastic strain arising early for the welded joint. The tempered martensite also induced a softening mechanism, which consists of the coarsening of martensite laths and a decrease of the dislocation density that reduces the movement of the dislocations. These phenomena have been previously reported in the literature [27]. To further analyze the hardening and softening behavior of the DP980 steel sheet and welded joints, Figure 13 presents the materials' cycle response in terms of the variable stress amplitudes during the LCF tests. The response for the DP980 steel sheet (Figure 13a) showed an initial hardening, which increased up to $760 \mathrm{MPa}$ for $\varepsilon_{a}=0.008$, followed by a minor softening until the final failure fracture. This mixed behavior can be observed in fatigue specimens evaluated at $\varepsilon_{a}=0.006$ and $\varepsilon_{a}=0.004$. This behavior has been reported elsewhere [21,28]. Furthermore, the damage in dual-phase steels is typically divided by hardening of the ferrite phase (increasing the hardening rate with increasing the strain amplitude) due to the dislocation structure, which blocks the movement and forms barriers for plastic deformation. As the cyclic strain continues, substructures form due to dislocation rearrangement (such as veins and cells), leading to softening [28,29]. In the case of the welded joint (Figure 13b), for $\varepsilon_{a}=0.008$ and $\varepsilon_{a}=0.006$ strain amplitudes, the welded joints show continuous cyclic softening. At lower strain amplitudes, the welded joint presented hardening followed by softening, without a definitive stable behavior. The hardening behavior is associated with lower cyclic stresses closer to the yield strength; thus, some hardening of the limited ferrite phase could be present. The diminution in the capacity of the weld joint hardening is attributed to the reduction of ferrite content. It is well known that the martensite phase is hard and brittle. For this reason, its capability to withstand cyclic strain is reduced compared with the ferrite phase. In fact, these results are similar to the obtained for quenched and tempered carbon steel [30]. This can be explained by the formation of unblocked dislocations and the creation of a fatigue substructure, inducing a reduction of the internal stress, as suggested by Sankaran et al. [30], who assessed a medium carbon microalloyed forging grade steel 38MnSiVS5 quenched and tempered steel under LCF conditions. 

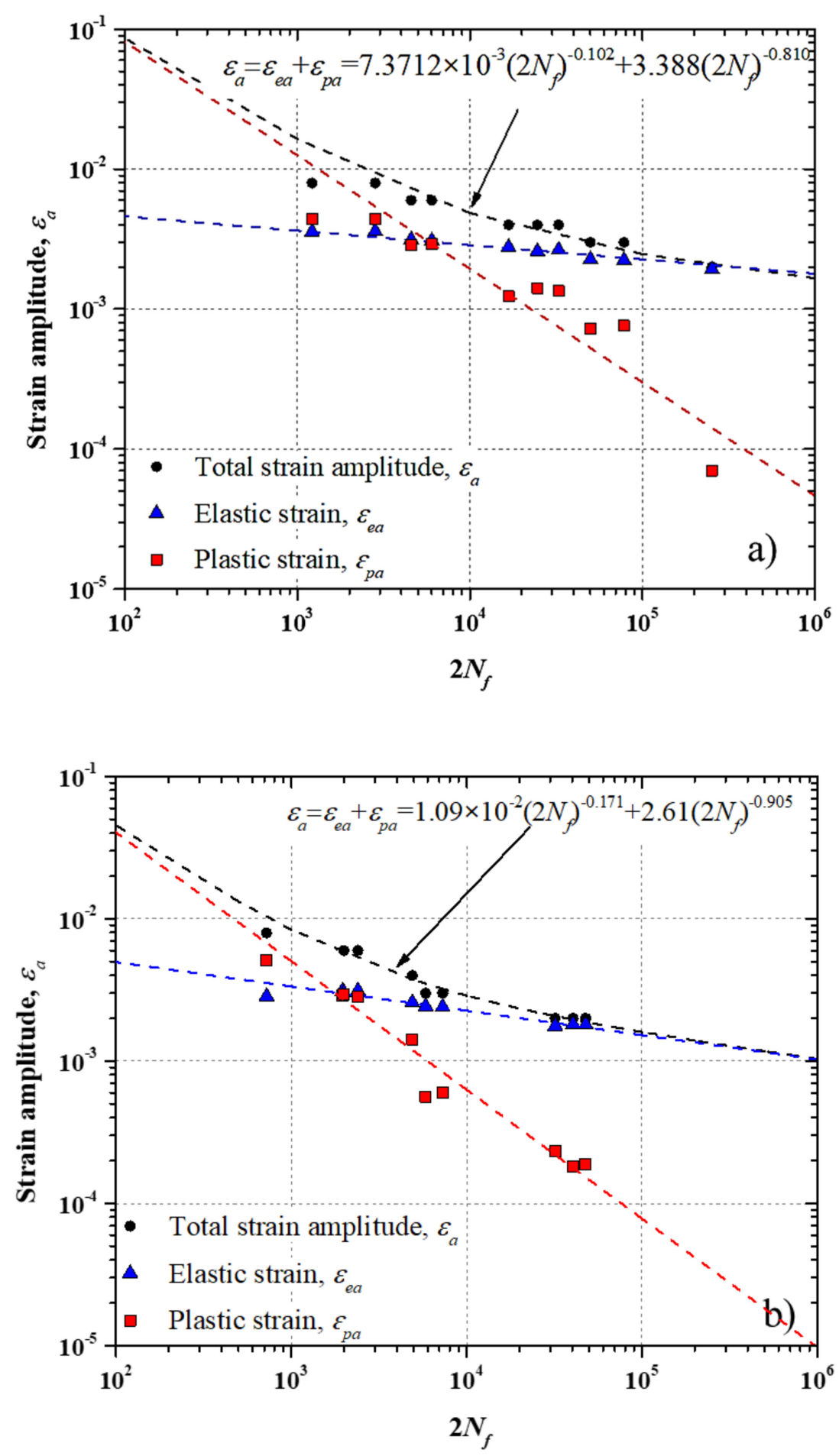

Figure 12. Total strain vs. $2 N_{f}$. (a) DP980 steel sheet and (b) welded joints. 

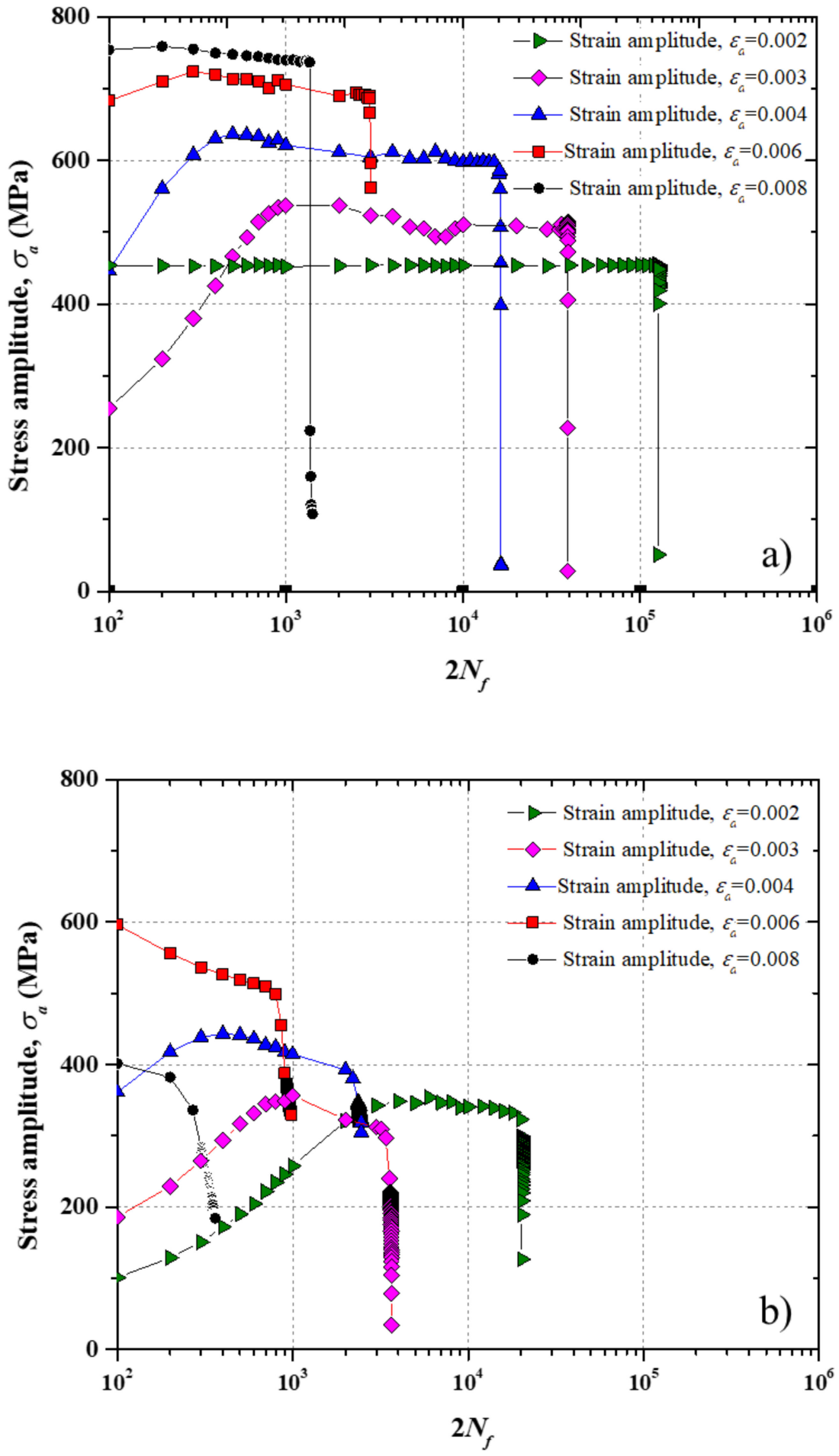

Figure 13. Variable stress amplitude vs. number of cycles at different strain amplitudes for: (a) DP980 steel sheet and (b) welded joints.

For completeness, $S-N$ curves for the DP980 steel sheet and welded joint deduced from the LCF tests are presented in Figure 14a,b. Table 5 presented the fatigue properties for the DP980 steel sheet and welded joint. Failure of fatigue samples took place at the LT-HAZ (Figure 14), since at this area, the tempered martensite requires the lowest stress to be deformed in the welded joint compared to the other martensite types located in the FZ and HT-HAZ. Therefore, the deformation distribution was not homogeneous, and it was concentrated at the position of the softened zone in the LT-HAZ (Figure 15). 

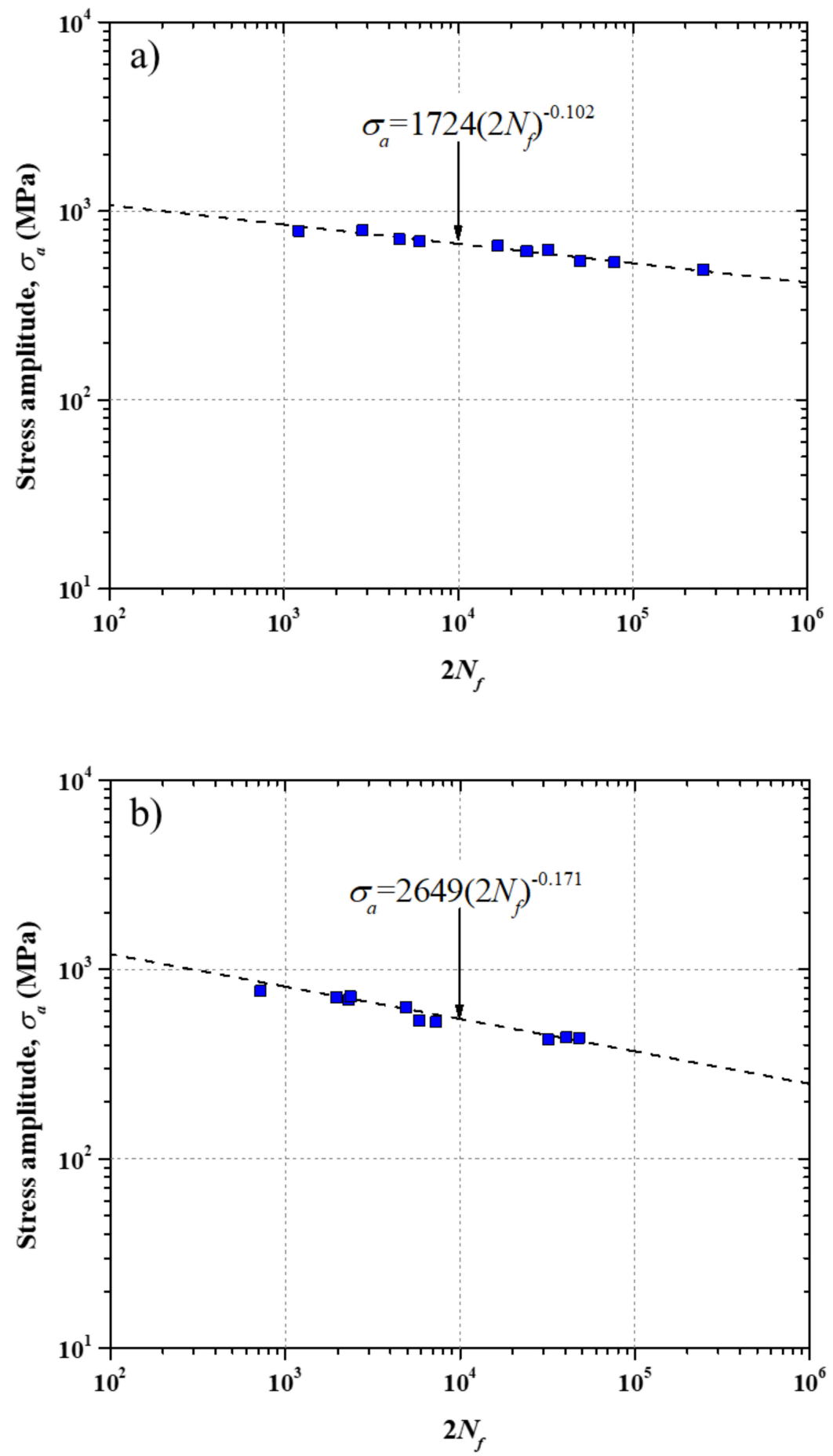

Figure 14. S-N curves of (a) DP980 steel sheet and (b) welded joints.

Table 5. Fatigue properties of the DP980 steel and welded joints.

\begin{tabular}{ccccc}
\hline Material & $\sigma_{f}^{\prime}$ & $\boldsymbol{b}$ & $\boldsymbol{\varepsilon}_{f}^{\prime}$ & $\boldsymbol{C}$ \\
\hline DP980 & 1724 & -0.102 & 3.388 & -0.810 \\
Welded joints & 2649 & -0.171 & 2.617 & -0.905 \\
\hline
\end{tabular}




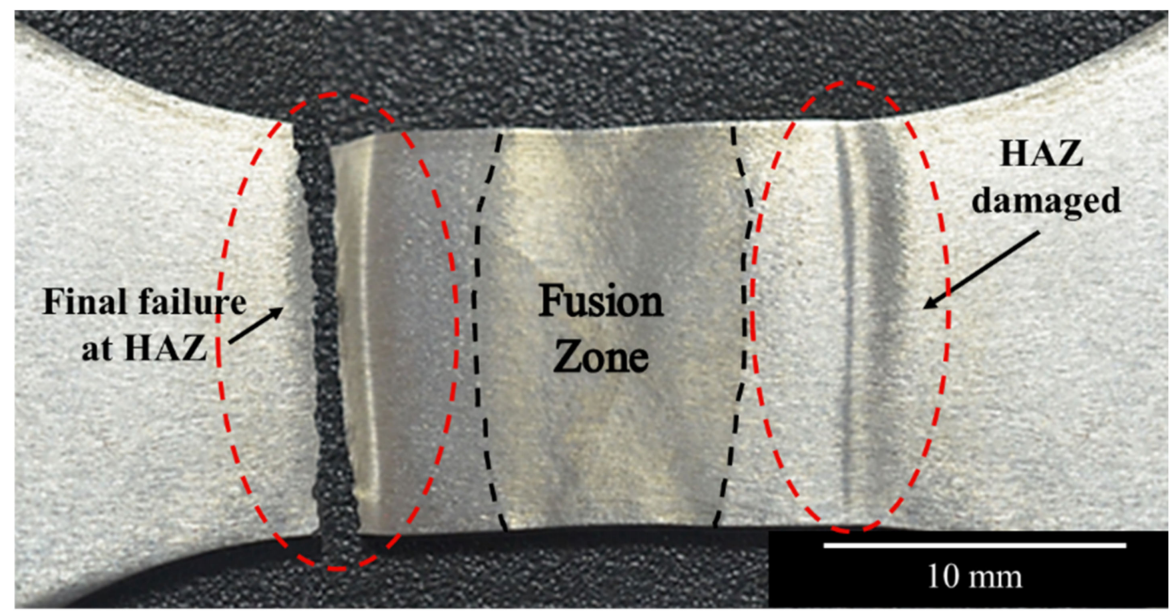

Figure 15. Failure zone of welded joints after LCF tests.

\subsection{Fractographic Analysis}

The evaluation of fracture surface was done by a Scanning Electron Microscope JEOL 6300, equipped with SEI (Secondary Electron Image) with an acceleration voltage of $20 \mathrm{keV}$. This analysis was carried out taking a welded joint sample evaluated in LCF at $\varepsilon_{a}=0.006$. This examination corresponds to the macroscopic and microscopic characteristics. The areas observed are marked with letters. In the macroscopic analysis of this fracture surface (Figure 16), in the LT-HAZ (where failure took place), plastic strain is evident at the edges where a thickness reduction is present. On the other hand, shear lips can be observed as a result of crack growth in the plane stress condition [31], attributed to the small thickness of the fatigue sample. Regarding the microscopic examination, the fracture exhibited ductile characteristics as observed in Figure 17a, where microvoids nucleation and coalescence was observed, which correspond with the final stage of fracture during the LCF test, and tear ridges are also shown as overload evidence due to the small remaining area when the crack length is critical. Deformation bands were observed at the edge of the tested fatigue sample, as shown in Figure $17 \mathrm{~b}$. A mixed fracture mode was present in some areas, where cleavage, quasi-cleavage, and microvoids coalescence were present. This was the main fracture mechanism found for most of the fracture surface, which was associated with a higher martensite content in this area and the presence of a ductile phase as ferrite (Figure 17c-e). Mainly cleavage was found in the area near the edge of the sample (Figure 17f). This characteristic can be found near the crack initiation point [31]. Furthermore, due to the tempered martensite content at this zone, cleavage is one of the mechanisms exhibited due to its brittle phase, and cleavage is a low energy fracture, as reported by Pandey et al. [32].

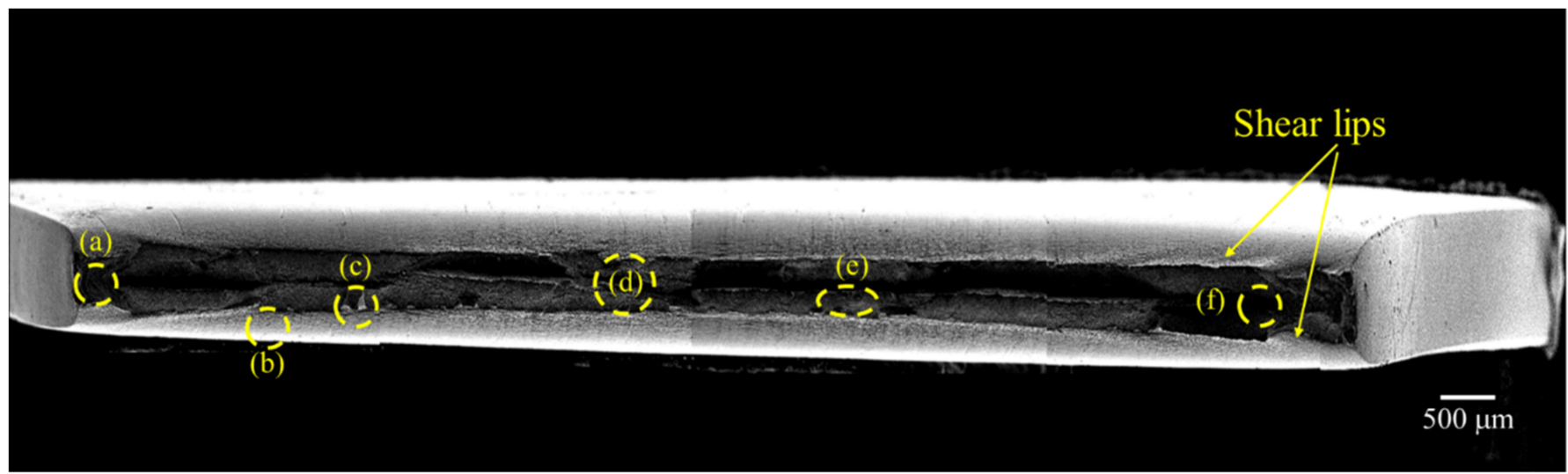

Figure 16. Sample tested at $\varepsilon_{a}=0.006$. The indications $(\mathbf{a}-\mathbf{f})$ correspond with the areas examined in the microscopic analysis. 

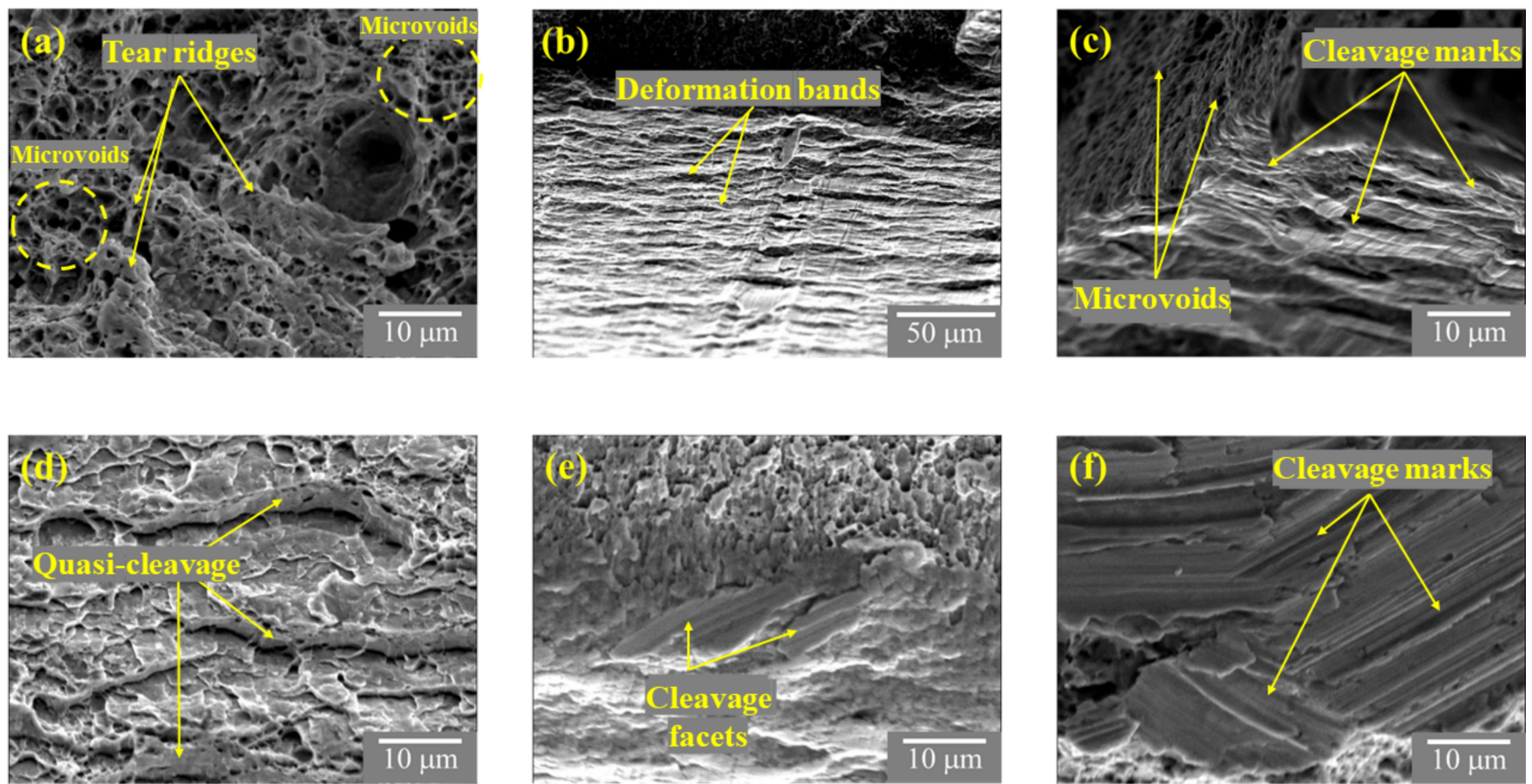

Figure 17. Details of different fracture features along the failed sample. (a) shows microvoids, (b) exhibits deformation bands at the outer face of a shear lip, (c) mixture of ductile and brittle zones at the inner wall of a shear lip, (d) quasi-cleavage, $(\mathbf{e}, \mathbf{f})$ evidence cleavage.

\section{Conclusions}

The main conclusions of this research work are the following:

- Dual phase sheet steel of $1.6 \mathrm{~mm}$-thick with a nominal tensile strength of $980 \mathrm{MPa}$ were properly welded by the GMAW process using a heat input of $302 \mathrm{~J} \cdot \mathrm{mm}^{-1}$. The welded joints exhibited full penetration and not discontinuities were presented;

- The dual martensite-ferrite phases were extensively modified by the GMAW process, presenting a martensite content increment of $54 \%$ in the HT-HAZ and $60 \%$ in the LTHAZ. A region of tempered martensite in the LT-HAZ produced a ductility reduction of $75 \%$ with respect to the DP980 steel sheet (base metal). Also, the hardness value was reduced by $\sim 20 \%$, and the tensile fracture was presented in this tempered martensite region. This tempering process of the martensite in the LT-HAZ was verified by metallography analysis and welded thermal cycles that showed that pre-existing martensite had not enough time to transform into new ferrite;

- Regarding the low cycle fatigue behavior, the strain-cycle data showed a reduced fatigue life for the welded joint compared to the dual-phase steel due to larger plastic strain amplitudes induced in the welded joint. For larger strain amplitudes $\left(\varepsilon_{a} \geq 0.6 \%\right)$, a softening behavior was observed in the welded joint during the LCF tests in terms of the variable stress amplitude as a function of the number of cycles to failure;

- On average, the fatigue life of the welded joint was reduced by $39 \%$ at strain amplitude $\varepsilon_{a} \geq 0.6 \%$. For the remaining strain amplitudes $(0.2,0.3$, and $0.4 \%)$, the welded joint exhibited a mixed behavior (hardening followed by softening), and only for the strain amplitude of $0.2 \%$, the welded joint presented cyclic stress-strain stable behavior. The fatigue life of the welded joint was reduced by $16 \%$ for the strain amplitudes of 0.2 , 0.3 , and $0.4 \%$. 
Author Contributions: Conceptualization, J.G.R.-C. and W.F.G.-Z.; methodology, J.G.R.-C. and W.F.G.-Z.; formal analysis, J.G.R.-C. and W.F.G.-Z.; investigation, J.G.R.-C.; resources, R.R.A. and D.J.; writing—original draft preparation, J.G.R.-C.; writing—review and editing, W.F.G.-Z., C.J.G., C.M.G. and R.R.A.; supervision, R.R.A., D.J., C.J.G., C.M.G.; project administration, R.R.A., D.J.; funding acquisition, R.R.A. All authors have read and agreed to the published version of the manuscript.

Funding: This research was funded by CONACYT-Mexico (Project A1-S-27474).

Data Availability Statement: The data presented can be available upon request to corresponding author.

Acknowledgments: The authors of this paper are very grateful for the support given by CONACYT to conduct doctoral studies of J.G.R.-C. and W.F.G.-Z. Also, the Centro de Investigación e Innovación Tecnológica of the IPN and SIP-IPN are acknowledged by the technical and academic support provided.

Conflicts of Interest: The authors declare no conflict of interest.

\section{Nomenclature}

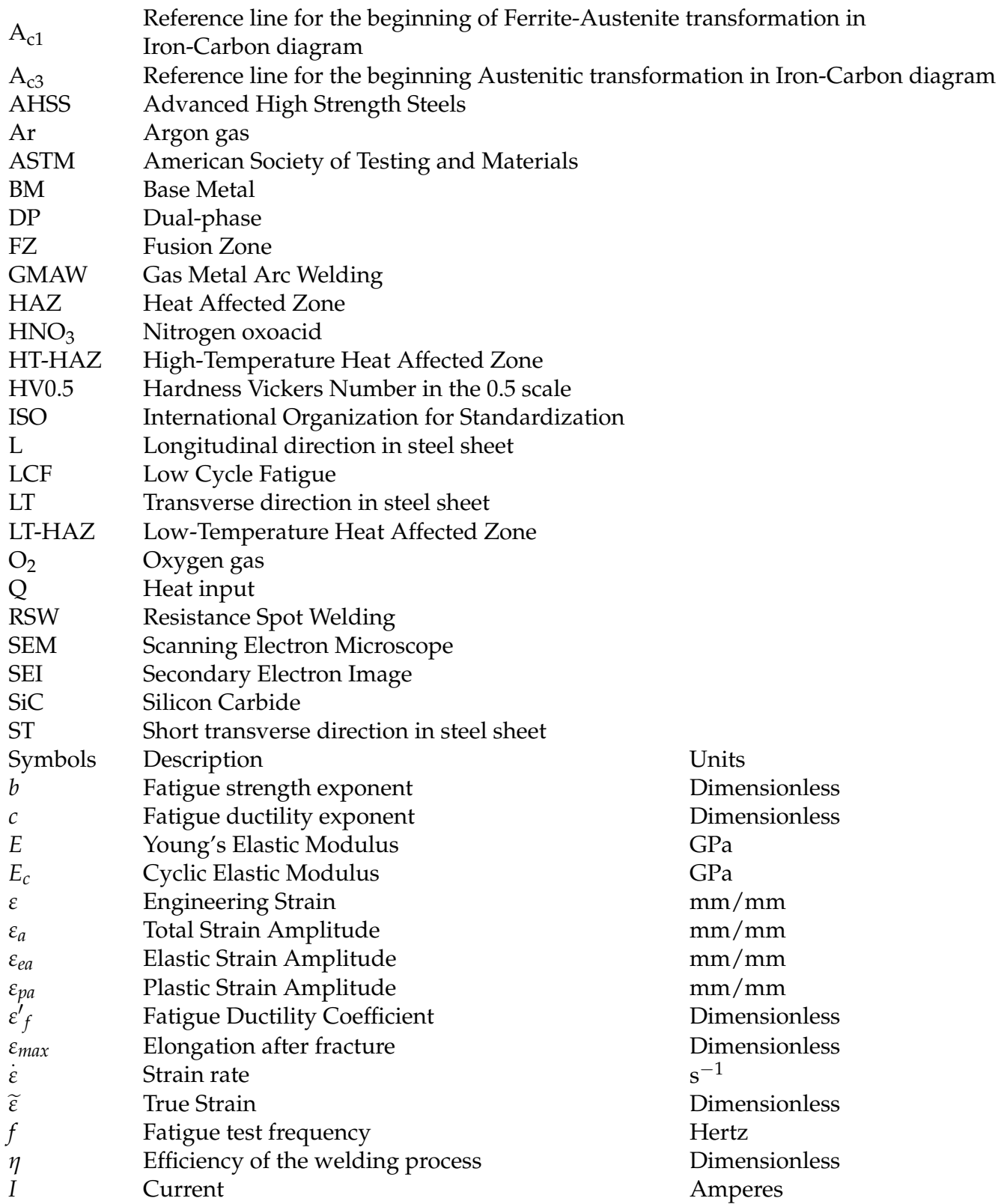




$\begin{array}{lll}\mathrm{J} & \text { Energy applied } & \text { Joules } \\ K & \text { Strength Coefficient } & \mathrm{MPa} \\ K^{\prime} & \text { Cyclic Strain Coefficient } & \mathrm{MPa} \\ \mathrm{KeV} & \text { Acceleration voltage } & \text { Kiloelectronvolts } \\ \mu \mathrm{m} & \text { Dimensions for scale in micrographs } & \text { Micrometers } \\ n & \text { Strain Hardening Exponent } & \text { Dimensionless } \\ n^{\prime} & \text { Cyclic Strain Hardening Exponent } & \text { Dimensionless } \\ \mathrm{N} & \text { Magnitude of force } & \text { Newton } \\ 2 N_{f} & \text { Reversals to Failure } & \text { Dimensionless } \\ v & \text { Speed of heat source } & \mathrm{mm} \cdot \mathrm{s}^{-1} \\ \sigma & \text { Engineering Stress } & \mathrm{MPa} \\ \widetilde{\sigma} & \text { True Stress } & \mathrm{MPa} \\ \sigma_{0.2} \% & \text { Offset Yield Strength } & \mathrm{MPa} \\ \sigma_{a} & \text { Stress Amplitude } & \mathrm{MPa} \\ \sigma_{f}^{\prime} & \text { Fatigue Strength Coefficient } & \mathrm{MPa} \\ \sigma_{u} & \text { Ultimate Tensile Strength } & \mathrm{MPa} \\ \sigma_{y}^{\prime} & \text { Offset Cyclic Yield Strength } & \mathrm{MPa} \\ R & \text { Fatigue ratio } & \mathrm{Dimensionless} \\ V & \text { Voltage } & \text { Volts }\end{array}$

\section{References}

1. Keeler, S.; Kimchi, M. Advanced High-Strength Steels Application Guidelines Version 6.0; World AutoSteel: Brussels, Belgium, 2014; Volume 6, p. 511.

2. Fonstein, N. "Dual-Phase Steels*," in Automotive Steels; Elsevier: Amsterdam, The Netherlands, 2017; pp. 169-216.

3. Davies, R.G. Influence of martensite composition and content on the properties of dual phase steels. Met. Mater. Trans. A 1978, 9 , 671-679. [CrossRef]

4. Dai, J.; Meng, Q.; Zheng, H. High-strength dual-phase steel produced through fast-heating annealing method. Results Mater. 2020, 5, 100069. [CrossRef]

5. Tasan, C.; Diehl, M.; Yan, D.; Bechtold, M.; Roters, F.; Schemmann, L.; Zheng, C.; Peranio, N.; Ponge, D.; Koyama, M.; et al. An Overview of Dual-Phase Steels: Advances in Microstructure-Oriented Processing and Micromechanically Guided Design. Annu. Rev. Mater. Sci. 2015, 45, 391-431. [CrossRef]

6. Kuziak, R.; Kawalla, R.; Waengler, S. Advanced high strength steels for automotive industry. Arch. Civ. Mech. Eng. 2008, 8 , 103-117. [CrossRef]

7. Ramazani, A.; Mukherjee, K.; Abdurakhmanov, A.; Prahl, U.; Schleser, M.; Reisgen, U.; Bleck, W. Micro-macro-characterisation and modelling of mechanical properties of gas metal arc welded (GMAW) DP600 steel. Mater. Sci. Eng. A 2014, 589, 1-14. [CrossRef]

8. Ahiale, G.K.; Oh, Y.-J. Microstructure and fatigue performance of butt-welded joints in advanced high-strength steels. Mater. Sci. Eng. A 2014, 597, 342-348. [CrossRef]

9. Easterling, K. Introduction to the Physical Metallurgy of Welding; Elsevier Ltd.: Amsterdam, The Netherlands, 2013; pp. 1-54.

10. Ordoñez, J.; Ambriz, R.; García, C.; Plascencia, G.; Jaramillo, D. Overloading effect on the fatigue strength in resistance spot welding joints of a DP980 steel. Int. J. Fatigue 2018, 121, 163-171. [CrossRef]

11. Kuril, A.A.; Ram, G.J.; Bakshi, S.R. Microstructure and mechanical properties of keyhole plasma arc welded dual phase steel DP600. J. Mater. Process. Technol. 2019, 270, 28-36. [CrossRef]

12. He, H.; Forouzan, F.; Volpp, J.; Robertson, S.; Vuorinen, E. Microstructure and Mechanical Properties of Laser-Welded DP Steels Used in the Automotive Industry. Materials 2021, 14, 456. [CrossRef]

13. Farabi, N.; Chen, D.; Zhou, Y. Fatigue properties of laser welded dual-phase steel joints. Procedia Eng. 2010, 2, 835-843. [CrossRef]

14. Xia, M.; Biro, E.; Tian, Z.; Zhou, Y.N. Effects of Heat Input and Martensite on HAZ Softening in Laser Welding of Dual Phase Steels. ISIJ Int. 2008, 48, 809-814. [CrossRef]

15. AWS D9 Committee on Welding, Brazing, and Soldering of Sheet Metal. D9.1/D9.1M:2000 Sheet Metal Welding Code. 2000. Available online: https://www.aws.org/standards/committee/d9-committee-on-sheet-metal-welding-2 (accessed on 1 December 2021).

16. Dupont, J.N.; Marder, A.R. Thermal efficiency of arc welding processes. Weld. J. 1995, 74, 406-416.

17. ESAB Spoolarc 120 Fact Sheet. Available online: https://www.esab.com.mx/mx/sp/products/filler-metals/mig-mag-wiresgmaw/low-alloy-wires/spoolarc-120.cfm (accessed on 1 December 2021).

18. West Conshohocken. ASTM E92-17, Committee E28.06 Test methods on Mechanical Testing. Standard Test Methods for Vickers Hardness and Knoop Hardness of Metallic Materials; West Conshohocken: Conshohocken, PA, USA, 2017. [CrossRef]

19. West Conshohocken. ASTM, E. 8, E28 Committee Test Methods for Tension Testing of Metallic Materials; ASTM International: West Conshohocken: Conshohocken, PA, USA, 2016. [CrossRef]

20. ISO 12106:2017 Metallic materials-Fatigue testing-Axial-Strain-Controlled Method, ISO/TC164/SC4 Technical Committee. Available online: https:/ / www.iso.org/standard/64687.html (accessed on 10 January 2022). 
21. Mediratta, S.; Ramaswamy, V.; Rao, P. Influence of ferrite-martensite microstructural morphology on the low cycle fatigue of a dual-phase steel. Int. J. Fatigue 1985, 7, 107-115. [CrossRef]

22. West Conshohocken. ASTM-E112, E4 Committee and Grain Size Measurements. Standard Test Methods for Determining Average Grain Size; West Conshohocken: Conshohocken, PA, USA, 2013.

23. Paul, S.K.; Stanford, N.; Hilditch, T. Effect of martensite volume fraction on low cycle fatigue behaviour of dual phase steels: Experimental and microstructural investigation. Mater. Sci. Eng. A 2015, 638, 296-304. [CrossRef]

24. Bombac, D.; Peet, M.J.; Zenitani, S.; Kimura, S.; Kurimura, T.; Bhadeshia, H.K.D.H. An integrated hot rolling and microstructure model for dual-phase steels. Model. Simul. Mater. Sci. Eng. 2014, 22, 45005. [CrossRef]

25. Cui, Q.L.; Parkes, D.; Westerbaan, D.; Nayak, S.S.; Zhou, Y.; Saha, D.C.; Liu, D.; Goodwin, F.; Bhole, S.; Chen, D. Tensile and Fatigue Properties of Single and Multiple Dissimilar Welded Joints of DP980 and HSLA. J. Mater. Eng. Perform. 2017, 26, 783-791. [CrossRef]

26. Sauraw, A.; Sharma, A.K.; Fydrych, D.; Sirohi, S.; Gupta, A.; Świerczyńska, A.; Pandey, C.; Rogalski, G. Study on Microstructural Characterization, Mechanical Properties and Residual Stress of GTAW Dissimilar Joints of P91 and P22 Steels. Materials 2021, 14, 6591. [CrossRef]

27. Saha, D.; Biro, E.; Gerlich, A.; Zhou, Y. Martensite tempering kinetics: Effects of dislocation density and heating rates. Mater. Charact. 2020, 168, 110564. [CrossRef]

28. Hadianfard, M.J. Low cycle fatigue behavior and failure mechanism of a dual-phase steel. Mater. Sci. Eng. A 2009, 499, 493-499. [CrossRef]

29. Suresh, S. Fatigue of Materials; Cambridge University Press: Cambridge, UK, 1998.

30. Sankaran, S.; Sarma, V.S.; Padmanabhan, K.A. Low cycle fatigue behavior of a multiphase microalloyed medium carbon steel: Comparison between ferrite-pearlite and quenched and tempered microstructures. Mater. Sci. Eng. A 2003, 345, 328-335. [CrossRef]

31. Anderson, T.L. Fracture Mechanics; CRC Press: Boca Raton, FL, USA, 2017.

32. Pandey, C.; Saini, N.; Mahapatra, M.M.; Kumar, P. Study of the fracture surface morphology of impact and tensile tested cast and forged (C \& F) Grade 91 steel at room temperature for different heat treatment regimes. Eng. Fail. Anal. 2017, 71, 131-147. [CrossRef] 